\title{
Experimental and numerical study of the behavior of LPG tanks exposed to wildland fires
}

\author{
Giordano Emrys Scarponi $^{a}$, Gabriele Landucci ${ }^{b}$, Frederic Heymes $^{c}$, \\ Valerio Cozzani ${ }^{a, *}$ \\ a LISES - Dipartimento di Ingegneria Civile, Chimica, Ambientale e dei Materiali, Alma Mater Studiorum - \\ Università di Bologna, via Terracini n. 28, 40131 Bologna, Italy \\ $\mathrm{b}$ Dipartimento di Ingegneria Civile e Industriale - Università di Pisa Largo Lucio Lazzarino 1, 56126 Pisa, Italy \\ c Ecole des Mines d'Ales, 30319 Alès, France
}

\section{A B S T R A C T}

The safety of small and medium LPG (liquefied petroleum gas) storage tanks in civil and industrial facilities when affected by forest fires in the framework of Wildland-Urban Inter-face (WUI) was investigated. Large scale experimental tests were carried to characterize the behavior of LPG tanks in case of distant source radiation caused by forest fires. A data set was obtained and used for the validation of a dedicated two-dimensional computational fluid dynamic (2D CFD) model for the analysis of pressure build-up in vessels exposed to different types of transient heat radiation, featuring different geometry types and operat-ing conditions. The combined experimental and numerical analysis allowed determining the critical exposure conditions for LPG vessels. Specific key performance indicators were defined and calculated on the basis of 2D CFD simulation results in order to derive conser-vative indications on failure conditions of LPG storage vessels induced by forest fires.

\author{
Keywords: \\ Forest fire \\ LPG tank \\ CFD modeling \\ Heat transfer \\ Liquid stratification \\ Distant source radiation \\ Wildland-Urban Interface
}

\section{Introduction}

Forest fires may cause relevant losses to residential structures, infrastructures, industrial facilities, farms, and vegetation, and constitute a relevant threat for human life (Alcasena et al., 2015; Argañaraz et al., 2017; Cardil and Molina, 2015; Dimitrakopoulos et al., 2011; LampinMaillet et al., 2009). This is a growing issue due to combined effects of climate change and to the spread of WUI (Wildland-Urban Interface) areas (Rossi et al., 2011). On the one side, climate change induces an increase in the occurrence of extreme fires, due the influence of air temperature and precipitations on ignition time, ignition temperature and moisture content of vegetation (Gill et al., 1978; Gray and Jenkins, 2017). On the other side, the spread of WUI zones implies more contact between vegetation and anthropic activities, leading to increment of ignition sources and consequent impact of wildfires on neighboring structures and people (Monedero et al., 2017; Zárate et al., 2008). Hence, relevant investment are needed for prevention and fire-fighting mea-

\footnotetext{
* Corresponding author.

E-mail address: valerio.cozzani@unibo.it (V. Cozzani).
}

sures (Lampin-Maillet et al., 2010). Research activities are devoted to the analysis of different aspects of the problem, in order to enhance the safety of people and environment.

Several previous studies were devoted to the identification and analysis of fire risk associated with WUI by characterizing the human and biophysical environment in critical areas. This allowed deriving strategies to set up suitable prevention actions and communication campaigns (Argañaraz et al., 2017; Keane et al., 2001; Lampin-Maillet et al., 2010, 2009; Pierce et al., 2009).

Beside the analysis of territory vulnerability, modeling fire propagation was as well addressed in order to trace the effects of the growing phase of fire, estimate the effectiveness of fuel treatments, ${ }^{1}$ develop suppression strategies, etc. (Lautenberger, 2013; Monedero et al., 2017) As indicated in (Gettle and Rice, 2002), radiant heat flux is the dominant heat transfer mechanism to structures along the WUI. Thus, in

\footnotetext{
1 The term "fuel treatment" describes any mechanical, sylvicoltural, or burning activity whose main objective is to reduce the thermal loadings or other vegetation characteristics to lessen fire behavior or burn severity in case of accidental ignition (Ager et al. 2010).
} 
this framework, a specific part of wildfire simulation and modeling was devoted to the estimation of heat radiation effects for the assessment of damage distances (Sullivan et al., 2003; Tran et al., 1992). Relevant modeling studies were carried out by (Billaud et al., 2011; Butler and Cohen, 1998; Zárate et al., 2008) showing either simplified or advanced heat radiation simulation tools. The outcomes of these modeling studies allow defining safety zones for people (e.g., fire-fighters), residential houses, and other buildings (e.g., factories and schools). Such zones must be established on the basis of thermal heat transfer from fire to the target as well as the behavior of the impacted target (Heymes et al., 2014, 2013a, 2013b)

Among the possible targets potentially affected by forest fire, small and medium scale LPG (liquefied petroleum gas) tanks represent a safety concern. LPG is commonly adopted for domestic purposes and above-ground storage tanks are located outside of houses. When exposed to severe distant source radiation induced by fire, LPG tanks may be subjected to severe heat-up and consequent pressurization, which may lead to the catastrophic rupture of the tank. This may be followed by severe scenarios, such as BLEVE (Boiling Liquid Expanding Vapor Explosion) (Reid, 1979), to which a blast wave (Abbasi and Abbasi, 2007) and fragment projection (Birk, 1995; Tugnoli et al., 2014a, $2014 b$ ) are associated. In case of ignition, a fireball may eventually occur (Maillette and Birk, 1996). These events may associate to wildfires in a residential area severe hazards for the population and for emergency teams, especially if fire-fighters are not aware of the presence of the LPG tank.

Due to the severity of the induced scenarios mentioned above, the escalation of accidents triggered by fires was object of several experimental and numerical studies carried out in the past decades (Dancer and Sallet, 1990; Droste and Schoen, 1988; Landucci et al., 2013; Moodie, 1988; Townsend et al., 1974). The aim of these studies was the analysis of industrial equipment or tankers adopted for hazardous materials transportation. In the majority of experimental campaigns, small or medium scale LPG tanks (volume ranging from 400 to $5000 \mathrm{~L}$ ) were adopted to analyze the heat-up induced by fire, consequent pressurization rate and eventually investigate the time to failure (Dancer and Sallet, 1990; Droste and Schoen, 1988; Landucci et al., 2013; Moodie, 1988). However, only hydrocarbon fires, such as pool or jet fires, featuring full or partial engulfment conditions, were simulated in the tests. Therefore, the heat-up and consequent pressurization rate of fired vessels were reproduced in conditions featuring relevant differences with respect to a forest fire exposure, thus without systematically addressing the effect of distant source radiation effects on small scale LPG tanks. Consequently, the development of modeling tools for the prediction of fired vessels response addressed this specific type of scenarios in order to obtain validated predictions.

The majority of lumped parameters codes developed in the past decades often considered full or partial tank engulfment (Hadjisophocleous et al., 1990; Lin et al., 2010; Salzano et al., 2003; Shebeko et al., 1995; Yu et al., 1992) despite the tools developed by (Heymes et al., 2013a; Landucci et al., 2009) also allowed simulating the exposure to steady state distant source radiation. In recent years, more detailed models for the simulation of LPG vessels exposed to fire were developed, based on computational fluid dynamics (CFD). However, in the studies presented by (Bi et al., 2011; D'Aulisa et al., 2014a, 2014b; Landucci et al., 2016), the simulation set up considered only full engulfment conditions, and the possible transient evolution of fire scenario was not systematically considered.

Moreover, it is worth mentioning that hydrocarbon flames (such as pool fires, jet fires, flares, etc.) have characteristics and properties which may remain constant during the fire event (Van Den Bosh and Weterings, 2005). On the contrary, the features of wildland fires can change due to the ground features (slope) and meteorological conditions, and may change in time (Zárate et al., 2008).

Therefore, testing and modeling the response of vessels under wildfire exposure conditions is a critical issue to be undertaken, and limited research efforts addressed this issues to date, at least to the best of our knowledge. In particular, Heymes et al. reproduced the effect of wildland fires on a small scale fire simulator (Heymes et al., 2013b), which allowed exposing a target LPG tank to realistic wildfire fire heat fluxes at the tank surface by adopting appropriate positioning. The scaling of large scale wildfire was the object of a dedicated study (Heymes et al., 2013b), which allowed determining the fire conditions in the small scale apparatus. Some preliminary experimental results were shown by (Heymes et al., 2014, 2013a, 2013b), which, however, adopted only a lumped parameters model in order to investigate the effect of fire exposure on the pressurization rate. Complex recirculation phenomena, the effect of vapor and liquid phase convective motion on the pressurization rate may only be captured through CFD analyses, also in the perspective of extending the simulation to different types of geometries and fire conditions.

Therefore, the object of the present study was the development of a 2D CFD model for the simulation of LPG tanks exposed to wildland fires. An extended experimental data set obtained through the wildfire simulator was adopted in order to validate the model, which was extended to the simulation of different fire configuration, geometries and operative parameters. Specific Key Performance Indicators (KPIs) were defined in order to obtain conservative but realistic considerations for the safety of fire-fighters in emergency response scenarios.

\section{Experimental set-up}

In 2013, Heymes et al. (2013a, 2013b) carried out an experimental campaign aimed at characterizing the thermal response of a $2.3 \mathrm{~m}^{3}$ cylindrical LPG tank to forest fire exposure.

Setting as reference a $100 \mathrm{~m}$ wide by $40 \mathrm{~m}$ high fire front with an average emissive power of $90 \mathrm{~kW} / \mathrm{m}^{2}$, they considered two different real scale forest fire scenarios, as reported in Table 1. In the first one, the LPG tank was positioned at $50 \mathrm{~m}$ from the fire front. In the second one, the distance was set to $28 \mathrm{~m}$. In order to reproduce such as large-scale scenario on a pilot and manageable scale, the authors performed a scale down of the problem. A simple homothetic transformation of the fire resulted not appropriate (i.e. scaling the problem geometry by maintaining the same ratio among all the dimensions: height/length of the fire front and tank-fire distance). In fact, since the tank was not scaled simultaneously, such transformation would have changed all angles of the rays exchanged between the fire and the tank. Heymes et al. (2013b) demonstrated that, at a scale suitable for experiments, this change determines a strong mismatch between the real and the scaled scenario in terms of two key parameters: the maximum incident heat flux and the total incident thermal power reaching the tank. Therefore, they carried out a large set of calculations aimed at finding the values of fire front dimensions and tank distance (changing the ratio among these dimensions) that provided the best possible agreement between real and experimental scale scenarios with respect to the above-mentioned parameters. The results of these calculations led to the definition of the most appropriate experimental geometric configurations corresponding to the real scale scenarios. The features of the test scale fires are reported in Table 1. An overview of the scaling procedure is reported in Appendix A.1, whereas further details are presented in (Heymes et al., 2013a, 2013b).

In the present study, experimental data gathered for fire scenario 1 were used for the validation of the 2D CFD results. Fire conditions related to scenario 2 were implemented for the analysis of the case studies (see Section 4).

The forest fire scenario was reproduced by means of a $3 \times 8 \mathrm{~m}$ steel wall equipped with a burners system consisting of five $50 \mathrm{~mm}$ pipes. Holes were drilled along the pipes in order to allow the outflow of the natural gas used to feed the fire. Fig. 1a shows the position of the fire wall and the tank. 
Table 1 - Definition of forest fire scenarios considered in the present study. Real scale indicates a fire scenario of actual dimensions reproduced in the small scale apparatus throuhg the similarity analysis shown in (Heymes et al., 2013b).

Parameter

Scenario 1

Scenario 2

Flame height $(\mathrm{m})$

Fire front length $(\mathrm{m})$

Tank distance (m)

Average emissive power $\left(\mathrm{kW} / \mathrm{m}^{2}\right)$

Maximum incident radiation $\left(\mathrm{kW} / \mathrm{m}^{2}\right)$

Total incident thermal power $(\mathrm{kW})$

\begin{tabular}{l} 
Sce \\
\hline Real scale \\
40 \\
100 \\
50 \\
90 \\
24 \\
84
\end{tabular}

Expe
33
8
3.8
90
26
80

\begin{tabular}{ll} 
& Scenario 2 \\
\hline Real scale & Experimental scale \\
40 & 3 \\
100 & 8 \\
28 & 2.8 \\
68 & 68 \\
41 & 42 \\
133 & 130
\end{tabular}

a Test adopted to obtain data for the validation of 2D CFD model.

a)

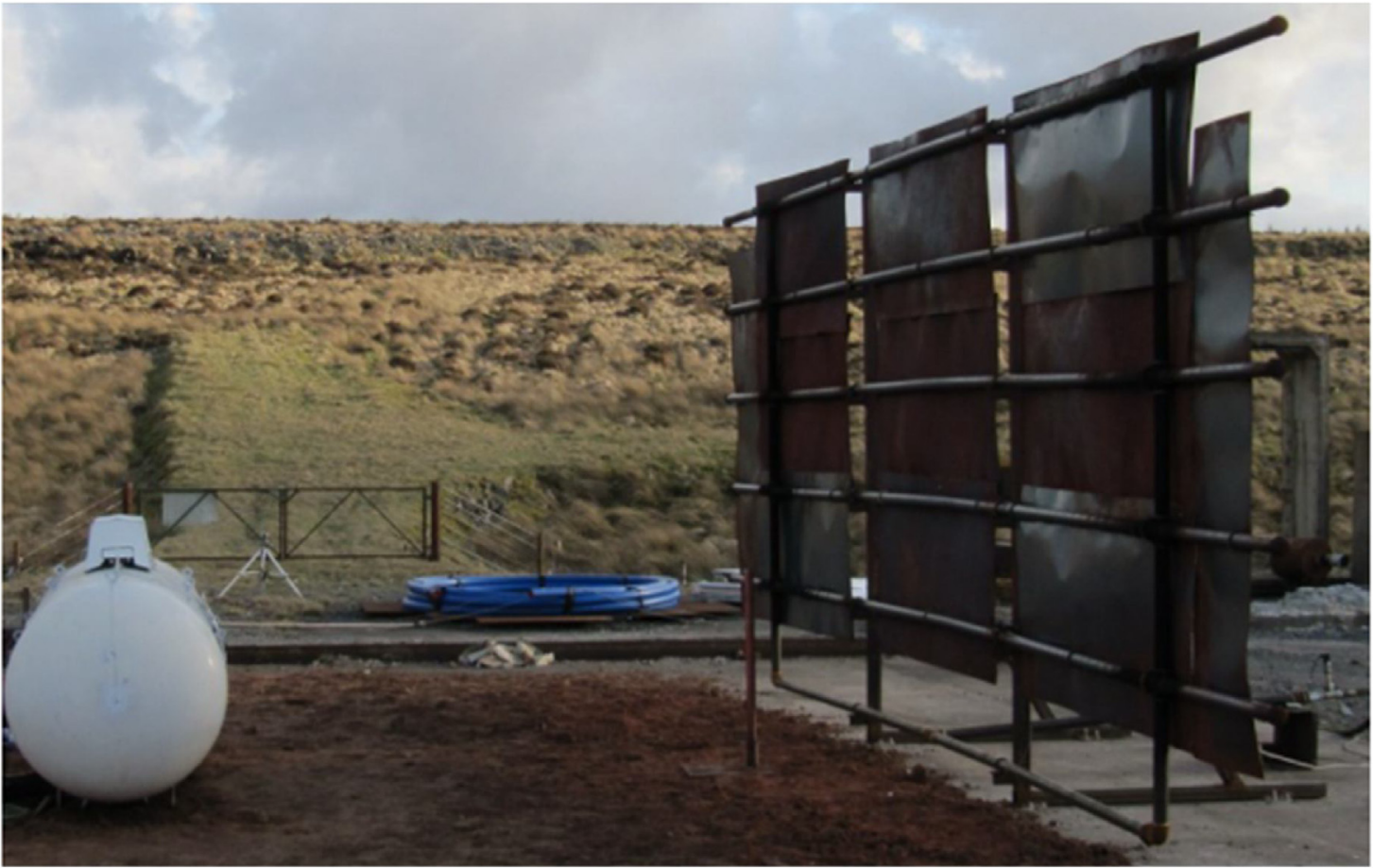

b)

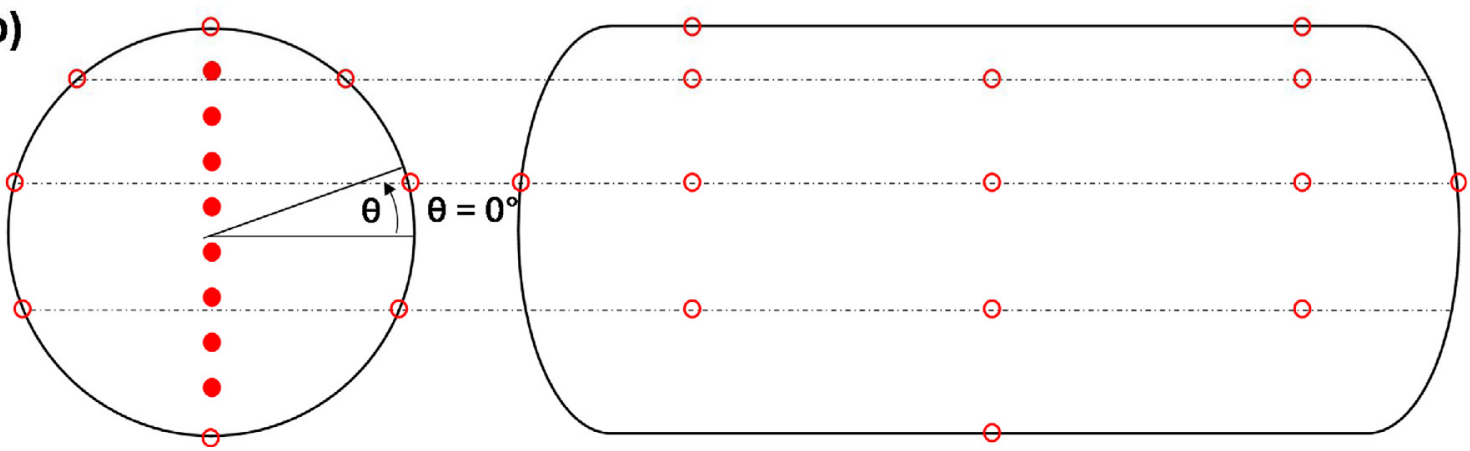

Fig. 1 - Experimental apparatus configuration. a) The steel wall to reproduce the fire scenatio is visible on the right; the tank is on the left. b) sketch of the thermocouples positioning in the lading (filled dots) and on the tank wall (empty dots).

The main test instrumentation consisted of:

23 type $\mathrm{K}$ thermocouples welded on the external wall of the tank aimed at measuring the external wall temperature;

- 8 type $\mathrm{K}$ thermocouples positioned inside the tank, along the vertical axis at the tank center aimed at measuring the lading temperature;

- 1 pressure gauge aimed at measuring the internal pressure in the vapor space;
- 2 radiative heat flux meters located in the points of maximum incident radiation, based on preliminary evaluations (see Heymes et al. (2013a) for more details)

Fig. 1b shows a sketch of the thermocouple positioning on the external wall (empty circles) and along a vertical at the center of the vessel (dots).

The LPG tank, with a nominal capacity of $2.30 \mathrm{~m}^{3}$, was made of carbon steel (A48P1) with a minimum wall thickness of $6.1 \mathrm{~mm}$, diameter of $1.0 \mathrm{~m}$ and total length of $2.6 \mathrm{~m}$. The tank 
was equipped with a pressure release valve (PRV) with a set point pressure of $19.6 \mathrm{barg}$.

\section{Numerical analysis}

\subsection{Overview of the modeling approach}

The thermal and fluid-dynamic response of the vessel exposed to forest fire radiation was modeled by means of a 2D transient CFD simulation implemented on ANSYS Fluent (ANSYS inc, 2012). Provided the appropriate boundary and initial conditions, the governing equations for mass, momentum and energy were solved for the tank lading, i.e. in the fluid, but also in the steel wall, thus in the solid domain.

Previously developed 2D CFD analyses of pressure buildup in LPG tanks exposed to fire (D'Aulisa et al., 2014a, 2014b; Landucci et al., 2016) were aimed at reproducing LPG tanks exposed to fully engulfing hydrocarbon pool fires, considering a steady and uniform heat source. Therefore, in the present study, relevant modifications were needed in order to reproduce the distant source radiation conditions obtained in the experimental set-up and to improve the previously developed models in order to better simulate the behavior of the boundary layer in a natural convection driven flow, avoiding the use of standard wall functions, as suggested by (Leuven, 2006). Moreover, it is worth mentioning that also low filling level values (e.g., <20\%) were simulated in this study, thus requiring an accurate assessment of the vapor phase with respect to previous literature studies, which were focused and validated against temperature distribution measured in the liquid phase (Bi et al., 2011; D'Aulisa et al., 2014b; Landucci et al., 2016). The main equations of the 2D CFD model are reported in Table 2, while the relevant improvements are summarized in the following. It is worth mentioning that a fully forward approach was used in setting up the 2D CFD simulations. Hence, no model parameters was tuned to the observed experimental results after their initial setting.

In natural convection flows, the Rayleigh number $(R a=g$ $\beta \Delta \mathrm{T} \mathrm{L}^{3} / \alpha$ ) dictates whether the flow regime is laminar $\left(R a<10^{9}\right)$ or turbulent $\left(R a>10^{9}\right)$, being $g$ is the gravity constant $\left(9.81 \mathrm{~m} / \mathrm{s}^{2}\right), \beta$ the thermal expansion coefficient, $\Delta T$ the temperature difference, $\alpha$ the thermal diffusivity and $L$ the characteristic length. In the case under analysis the Rayleigh number for both liquid and vapor phase is higher than $10^{13}$, since: (i) L may be assumed as the internal diameter of the tank (thus, $L \approx 1-2 \mathrm{~m}$ ); (ii) a limited temperature difference between the wall and the bulk is obtained in this case from experimental evidence $(\Delta T \approx 1 \mathrm{~K})$; and (iii) LPG may be assumed as pure propane, with material properties in the saturation conditions at 0.7 MPa estimated from literature data (Liley et al., 1999). Therefore, being well beyond the threshold below which the flow is laminar, the application of a turbulence model was needed.

In order to obtain accurate results for the heat transfer at the wall, the use of a turbulence model able to solve the governing equation inside the boundary layer was preferred with respect to a wall function approach, adopted in previous studies (Bi et al., 2011; D'Aulisa et al., 2014a, 2014b; Landucci et al., 2016; Zheng et al., 2013, 2012). The turbulence model selected was the k- $\omega$ SST (Launder and Spalding, 1972). This requires a $^{+}$around to 1 in the first cell close to the wall, (where $\mathrm{y}^{+}$is the dimensionless distance from the wall).
Due to the presence of two immiscible phases, the Volume Of Fluid (VOF) was selected as multiphase model, in accordance with a previously developed approach (D'Aulisa et al., 2014a, 2014b; Landucci et al., 2016). This solves a single set of momentum equations and tracks the volume fraction of each of the fluids. The vapor phase was chosen as the primary one, as suggested in (ANSYS inc, 2012) to avoid convergence problems.

Fluid properties are expressed as a function of temperature according to thermodynamic data provided in (Liley et al., 1999). The same dataset was adopted for the determination of the saturation pressure used in the evaporation/condensation model described in Section 3.2. The Soave-Redlich-Kwong equation of state was used for the vapor phase density calculation. The thermal properties of low carbon steel and their variation as a function of temperature were taken from Eurocode 1 (European Commission, 2005).

\subsection{Evaporation and condensation model}

The mass transfer between the two phases was simulated by using the evaporation-condensation model implemented in Fluent and based on the work of Hertz-Knudsen (Knudsen, 1934). Evaporation will occur in a given cell when the temperature is above the saturation temperature (calculated at the cell pressure) according to Eq. (1) (where $m_{\mathrm{L} \rightarrow \mathrm{V}}=$ evaporation liquid phase source term; $\alpha=$ phase volumetric fraction, $\rho=$ density, $\mathrm{T}=$ cell temperature, $T_{\text {sat }}=$ cell saturation temperature, $C_{E}$ and $C_{C}=$ coefficients, the subscripts $\mathrm{L}$ and $\mathrm{V}$ indicate the liquid and the vapor phase, respectively):

$$
\begin{aligned}
& m_{L \rightarrow V}=C_{E} \alpha_{L} \rho_{L}\left(\frac{T-T_{\text {sat }}}{T_{\text {sat }}}\right) \\
& m_{V \rightarrow L}=C_{C} \alpha_{V} \rho_{V}\left(\frac{T_{\text {sat }}-T}{T_{\text {sat }}}\right)
\end{aligned}
$$

On the contrary, when the cell temperature is below the saturation temperature, part of the content of the cell will condense according to Eq. (2) (where $m_{V \rightarrow L}=$ condensation liquid phase source term). Coefficients $C_{E}$ and $C_{C}$ are the mass transfer time relaxation parameters and are aimed at representing the rate of evaporation and condensation, respectively. In the literature, these coefficients are usually set to 0.1 (e.g. see Wu et al., 2007). The same values were employed in a previous study (D'Aulisa et al., 2014b) obtaining promising results in the simulation of large scale tankers engulfed in pool fire. Thus, both values were used also in the present study. It is worth mentioning that both $\mathrm{C}_{\mathrm{E}}$ and $\mathrm{C}_{\mathrm{C}}$ depend on the physical and chemical properties of the substance under analysis (LPG in this case) and are not influenced by the geometry of the problem.

The presence of the vapor volume fraction in Eq. (1) ensures that condensation cannot occur in a cell full of liquid (thus with $\alpha_{V}=0$ ). On the same time, the presence of the liquid volume fraction in Eq. (2) ensures that evaporation is not possible in a cell full of vapor (thus with $\alpha_{V}=1$ ).

\subsection{Boundary conditions}

The aim of the present 2D CFD model is to predict the response of an LPG tank to a given and well-defined forest fire scenario, which effect is implemented as boundary condition for the energy equation. The complete simulation of the forest fire is out of the scope of the present study. 


\section{Table 2 - Governing equation for turbulent, two phases, transient 2D CFD simulation.}

\begin{tabular}{|c|c|}
\hline Property & Equations \\
\hline $\begin{array}{l}\text { Volume fraction of the } \\
\text { secondary phase (liquid) }\end{array}$ & $\begin{array}{l}\frac{1}{\rho_{\mathrm{L}}}\left[\frac{\partial}{\partial \mathrm{t}}\left(\alpha_{\mathrm{L}} \rho_{\mathrm{L}}\right)+\nabla \cdot\left(\alpha_{\mathrm{L}} \rho_{\mathrm{L}}\langle\mathbf{u}\rangle\right)=m_{\mathrm{V} \rightarrow \mathrm{L}}-m_{\mathrm{L} \rightarrow \mathrm{V}}\right] \\
\rho_{\mathrm{L}}: \text { liquid density; t: time; } \boldsymbol{\alpha}_{\mathrm{L}}: \text { liquid volume fraction; }\langle\mathbf{u}\rangle \text { : ensemble averaged velocity; } m_{\mathrm{V} \rightarrow \mathrm{L}}: \text { condensation liquid } \\
\text { phase source term (see Eq. (2)); } m_{\mathrm{L} \rightarrow \mathrm{V}} \text { : evaporation liquid phase source term (see Eq. (1)); }\end{array}$ \\
\hline $\begin{array}{l}\text { Volume fraction of the } \\
\text { primary phase (vapor) }\end{array}$ & $\begin{array}{l}\alpha_{\mathrm{V}}=1-\alpha_{\mathrm{L}} \\
\alpha_{\mathrm{V}}: \text { vapor volume fraction }\end{array}$ \\
\hline Momentum & $\begin{array}{l}\frac{\partial}{\partial t}(\rho\langle\mathbf{u}\rangle)+\nabla \cdot(\rho\langle\mathbf{u}\rangle\langle\mathbf{u}\rangle)=-\nabla\langle\mathbf{P}\rangle+\rho \mathbf{g}+\nabla \cdot\left[\mu\left(\nabla\langle\mathbf{u}\rangle+(\nabla\langle\mathbf{u}\rangle)^{\mathrm{T}}-\frac{2}{3} \nabla \cdot\langle\mathbf{u}\rangle \mathrm{I}\right)\right]-\nabla \cdot\left(\rho\left\langle\mathbf{u}^{\prime} \mathbf{u}^{\prime}\right\rangle\right) \\
\rho \text { : two-phase volume fraction averaged density; }\langle\mathbf{P}\rangle: \text { ensemble averaged pressure; } \mathbf{u}^{\prime}: \text { instantaneous velocity } \\
\text { fluctuation; } \mu \text { : two-phase averaged viscosity; g: gravity acceleration; I: identity tensor. }\end{array}$ \\
\hline Energy (fluid domain) & $\begin{array}{l}\frac{\partial}{\partial t}(\rho e)+\nabla \cdot[\langle\mathbf{u}\rangle(\rho e+\langle p\rangle)]=\nabla \cdot\left(k_{\text {eff }} \nabla T\right)+\lambda\left(m_{V \rightarrow L}-m_{L} \rightarrow V\right) \\
e: \text { two-phase ensemble averaged specific energy; } k_{\text {eff: }} \text { effective thermal conductivity; } \lambda \text { : heat of vaporization. }\end{array}$ \\
\hline Energy (solid domain) & $\begin{array}{l}\frac{\partial}{\partial t}\left(\rho_{S} C p_{S} T_{S}\right)=\nabla \cdot\left(k_{S} \nabla T_{S}\right) \\
T_{S}: \text { temperature in the solid; } k_{S} \text { : steel thermal conductivity; } \rho_{S} \text { steel density; } C p_{S} \text { steel heat capacity }\end{array}$ \\
\hline Turbulent kinetic energy & $\begin{array}{l}\frac{\partial}{\partial t}(\rho K)+\nabla \cdot(\rho K\langle\mathbf{u}\rangle)=\nabla \cdot\left[\left(\mu+\frac{\mu_{T}}{\sigma_{K}}\right) \nabla K\right]+G_{K}-Y_{K} \\
K \text { : turbulent kinetic energy; } \mu_{T} \text { : two-phase averaged turbulent viscosity; } \sigma_{K} \text { : turbulent Prandtl number for } K ; G_{K} \text { : } \\
\text { generation of } K \text { due to mean velocity gradients; } Y_{K} \text { : dissipation of } K \text { due to turbulence. The definitions of } \sigma_{K}, G_{K} \\
\text { and } Y_{K} \text { can be found in (ANSYS inc, 2012) }\end{array}$ \\
\hline $\begin{array}{l}\text { Turbulent specific } \\
\text { dissipation rate }\end{array}$ & $\begin{array}{l}\frac{\partial}{\partial t}(\rho \omega)+\nabla \cdot(\rho \omega\langle\mathbf{u}\rangle)=\nabla \cdot\left[\left(\mu+\frac{\mu_{T}}{\sigma_{\omega}}\right) \nabla \omega\right]+G_{\omega}-Y_{\omega} \\
\omega \text { : turbulent specific dissipation rate; } \sigma_{\omega} \text { : turbulent Prandtl number for } \omega \text {; } G_{\omega} \text { : generation of } \omega \text {; } Y_{\omega} \text { : dissipation of } \\
\omega \text {. The definitions of } \sigma_{\omega}, G_{\omega} \text { and } Y_{\omega} \text { can be found in (ANSYS inc, 2012) }\end{array}$ \\
\hline Turbulent viscosity & $\begin{array}{l}\mu_{\mathrm{T}}=\frac{\rho K}{\omega} \frac{1}{\max \left[\frac{1}{\alpha^{*}} \cdot \frac{S F_{2}}{\alpha_{1} \omega}\right]} \\
\text { The definitions of } \alpha^{*}, S, F_{2} \text { and } \alpha, \text { can be found in (ANSYS inc, 2012) }\end{array}$ \\
\hline $\begin{array}{l}\text { Two-phase averaged } \\
\text { quantity }\end{array}$ & $\begin{array}{l}\quad=\alpha_{\mathrm{L}} \psi_{\mathrm{L}}+\left(1-\alpha_{\mathrm{L}}\right) \psi_{\mathrm{V}} \\
\text { Two-phase volume fraction averaged property } \Psi \text { function of liquid and vapor properties ( } \Psi_{\mathrm{L}} \text { and } \Psi_{\mathrm{V}} \text {, } \\
\text { respectively) where } \Psi \text { can be density } \rho \text {, viscosity } \mu \text {, turbulent viscosity } \mu_{\mathrm{T}} \text {, thermal conductivity } k \text {. }\end{array}$ \\
\hline $\begin{array}{l}\text { Effective thermal } \\
\text { conductivity }\end{array}$ & $\begin{array}{l}k_{\text {eff }}=k+\frac{c_{p} \mu_{T}}{P_{T}} \\
k=\text { two-phase volume fraction averaged thermal conductivity } c_{p} \text { : two-phase volume fraction averaged heat } \\
\text { capacity } \operatorname{Pr}_{T} \text { : turbulent Prandtl number }=0.85 \text { (Tu et al., 2013) }\end{array}$ \\
\hline
\end{tabular}

When a tank is exposed to a distant source radiation as a fire, heat from the flame is transferred mostly by radiation. Considering the fire as an emitting surface with a constant equivalent black body temperature $\left(T_{F, B B}\right)$ and neglecting the radiation absorbed by the air, the incident radiation $\left(I_{P}\right)$ at point $P$ on the tank surface can be expressed as follows:

$I_{P}=\sigma \times \zeta$

$\zeta=f_{P \rightarrow F} T_{F, B B}{ }^{4}+\left(1-f_{P \rightarrow F}\right) T_{\infty}^{4}$

where $\sigma$ is the Stefan-Boltzmann constant, $T_{\infty}$ is the temperature of the surrounding and $f_{\mathrm{P} \rightarrow F}$ is the view factor between point $P$ and the fire. The procedure for calculating $f_{P \rightarrow F}$ is explained in detail in Appendix A.

Although the CFD simulation of the tank interior was carried out in 2D (i.e. considering the tank as a cylinder with an infinite dimension in the axial direction), the calculation of the view factors in Eq. (3b) required a preliminary threedimensional (3D) modeling by ANSYS Fluent. This was carried out using the S2S (surface to surface) radiation model (ANSYS inc, 2012), as detailed in Appendix A.

The fire scenario geometries where reproduced as showed in Fig. 2a, taking advantage of the geometric similitude presented in Table 1. In particular, the values of the view factors (see Fig. 2c) at the line indicated as $\mathrm{x}_{0}$ in Fig. $2 \mathrm{~b}$ were of interest for the present case. It was thus possible to define a black body temperature equivalent to the term $\zeta$ defined in Eq. (3b). This was passed to the solver by means of a dedicated User Defined Function (UDF), which is reported in Appendix A.3.
The solver calculates the entering heat flux (q)for each point at the external tank wall as follows:

$$
q(\theta, t)=\sigma \varepsilon_{w}\left(T_{B B, e q}(\theta)^{4}-T_{w}(t)^{4}\right)
$$

where $\varepsilon_{w}$ is the wall emissivity (a value of 0.77 , measured in the fire test (Heymes et al., 2013a), was used in all the simulations) and $T_{w}$ is the temperature of a given point at the external tank wall. Clearly, this heat flux is a function of time (the wall temperature changes during the calculation) and the angle $\theta$ as defined in Fig. 2c.

Furthermore, since the temperature of the fire wall did not remain constant during the experiment, the measurement provided by the radiative flux meter (Fig. 2d) was also taken into account in the definition of term $\mathrm{T}_{\mathrm{BB}, \text { eq }}$ in Eq. (4) when the experimental case was simulated. Since the heat flux measurements signal was affected by noise, as evident in Fig. 2d, a specific data smoothing was carried out on heat flux data to make them suitable for UDF implementation. The data smoothing shown in Fig. $2 \mathrm{~d}$ was carried out using weighted linear least squares and a first-degree polynomial model in order to obtain a local regression.

An important point raised during the treatment of boundary conditions was related to the assessment of the convective heat flux contribution to the total heat transfer mechanism. In particular, detailed temperature and velocity measurements of the air surrounding the tank are needed for the evaluation of the convective heat transfer coefficient. These are relevant factors which are expected to change in time during fire exposure and according to the location, due to the relevant asymme- 


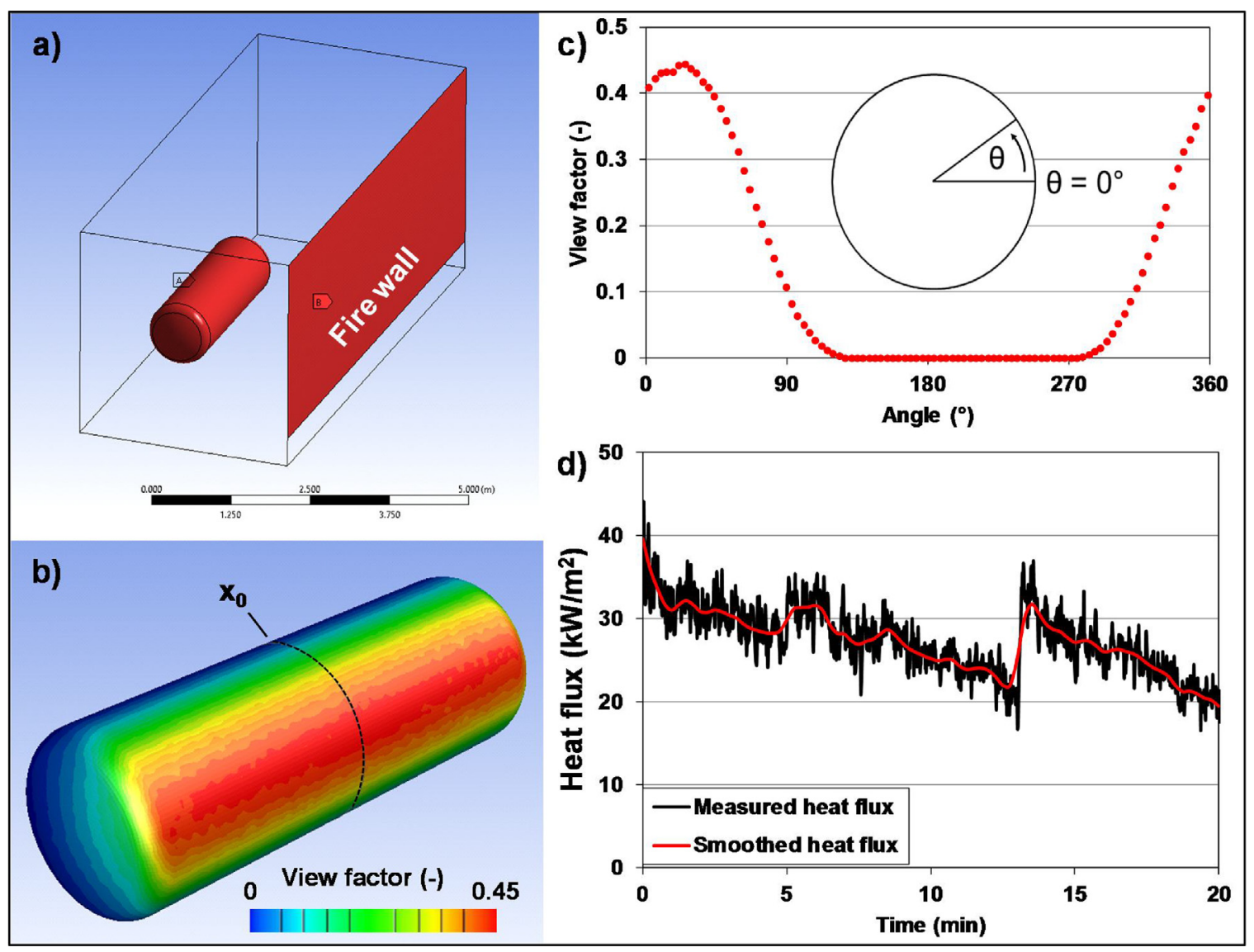

Fig. 2 - Boundary condition definition process: 3D geometry for view factors calculation (a), contour plot of the view factor (b), view factors on the section $x_{0}$ as a function of the angle $\theta$ (see Fig. 1) (c), measured and smoothed heat flux obtained by the flux meter (d). The boundary conditions are implemented in FLUENT through the UDF reported in Appendix A.3.

try featured by the present case (vessel exposed only on one side to distant source radiation). However, due to the absence of such necessary information, which was not recorded in the experimental test, implementing natural convection in the model would have introduced further uncertainties in the input parameters. Therefore, the heat transferred to the surrounding air by natural convection was neglected. It is worth pointing out that this choice is on the safe side, since the convective contribution would subtract heat from the tank, thus lowering the heat-up process and the consequent pressurization rate.

However, for the sake of completeness, a specific simulation was performed assuming some credible values for air temperature and convective heat transfer coefficient either to verify the validity of the present assumption or to trace the effect of the natural convection on the simulation results. Thus, beside the radiative input heat flux (q, see Eq. (4)), a convective term $\left(q_{c}\right)$ was introduced, expressed as follows:

$q_{c}(\theta, t)=h_{\text {air }}\left(T_{w}(\theta, t)-T_{a}\right)$

where $T_{a}$ is the ambient temperature assumed equal to the initial temperature of the simulation, and $h_{\text {air }}$ is the convective heat transfer coefficient between the external wall and the surrounding air (neglecting possible effects due to wind). This latter parameter was estimated through the empirical correlation reported by (Martynenko and Khramtsov, 2005) for the calculation of the natural convection heat transfer coefficient around a horizontal cylinder:

$\mathrm{Nu}=0.13 \mathrm{Ra}^{1 / 3}$

where $\mathrm{R} a$ is the Rayleigh number and Nu is the Nusselt number $\left(\mathrm{Nu}=\frac{h_{\text {air }} L}{k_{\text {air }}}\right.$; where $L$ is the characteristic length and $k_{\text {air }}$ is the thermal conductivity of the air). In particular, $h_{\text {air }}=5 \mathrm{~W} /\left(\mathrm{m}^{2} \mathrm{~K}\right)$ was imposed in the simulations. This average value was estimated by considering a temperature difference between the wall and the air ranging between 0 and $200^{\circ} \mathrm{C}$, and assuming the tank diameter as characteristic length $\mathrm{L}$.

Finally, the initial temperature condition for the simulation of the experimental test and for the analysis of the case studies defined in Section 4 was set to $13^{\circ} \mathrm{C}$.

\subsection{Solution methods}

For what concern the transient formulation in ANSYS Fluent, a first order implicit scheme was adopted, with a timestep of $5 \mathrm{~ms}$. A halved time step $(2.5 \mathrm{~ms})$ was also applied in order to check time step independence. A second order upwind scheme was chosen for the spatial discretization of density, momentum, energy and turbulent quantities ( $\mathrm{k}$ and $\omega$ ), whereas the PRESTO! and the Geo-Reconstruction schemes were used for the pressure and the volume fraction respectively (ANSYS inc, 2012). Pressure and velocity coupling was obtained by means of the SIMPLEC (Semi-Implicit Method for Pressure Linked Equations-Consistent) algorithm. At each 


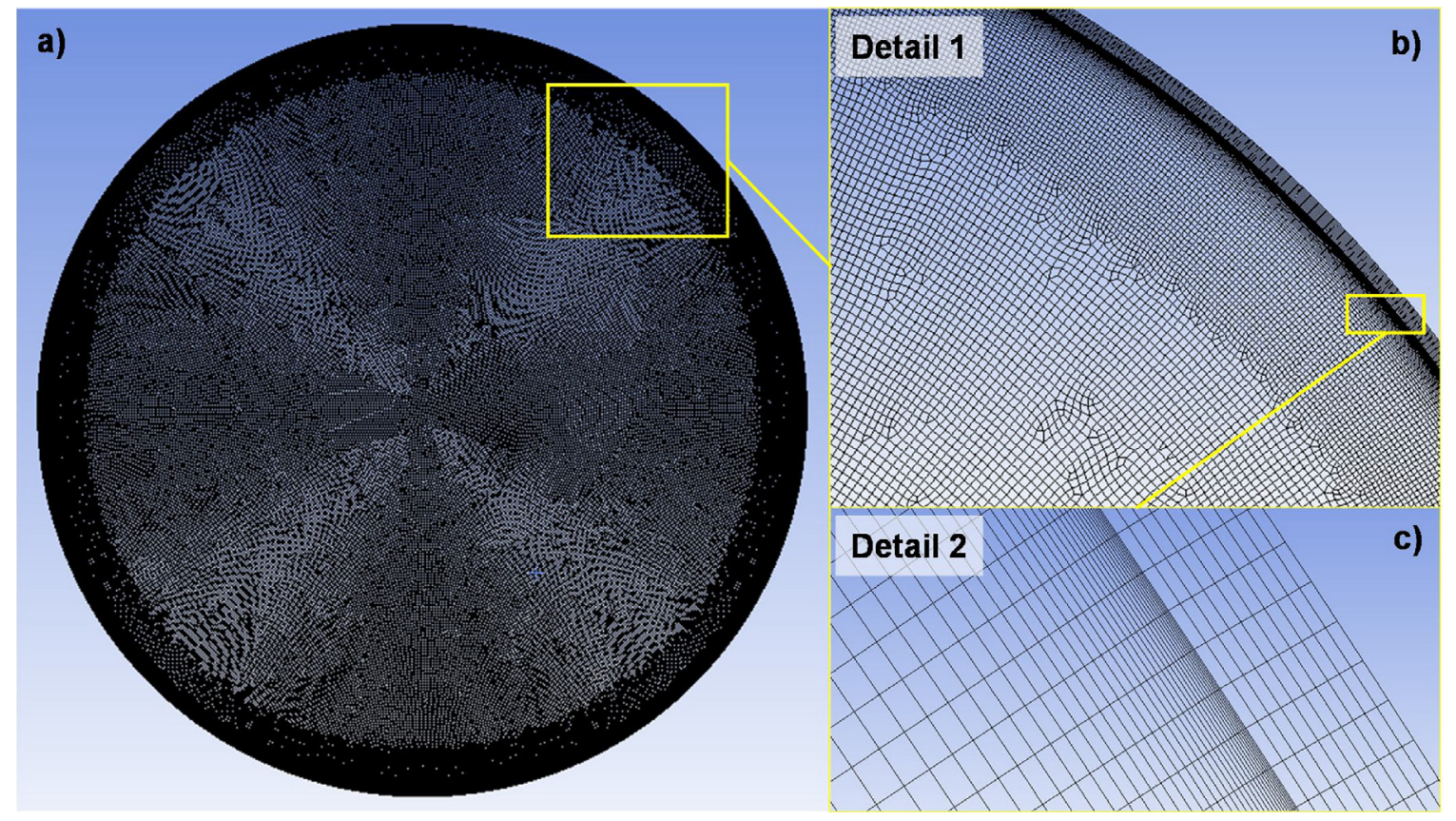

Fig. 3 - Mesh adopted for the simulation of the case studies: a) overview; b) detail 1; c) detail 2.

time step, the solution was considered converged when one of the following criteria was satisfied:

- The sum of the scaled residuals was below $10^{-3}$

- For a given time step, the ratio between the residuals and the residuals at the beginning of the time step was below 0.05

The calculation domain of the present 2D CFD model includes only the tank, both steel wall and the lading, and was discretized into an unstructured mesh featuring 155,745 cells. The maximum cell size was $3.3 \mathrm{~mm}$. In order to ensure a good resolution in the near wall region, 50 inflation layers were built starting from the inner wall of the tank. The first layer was $50 \mu \mathrm{m}$ and the growth rate throughout the inflation was set to 1.1. The circles representing the inner and the outer wall were divided in 1500 elements. Fig. 3 show the entire mesh and the inflation layer in the near wall region. A finer mesh with 264,993 cells (1.7 times the cell of the first mesh) was also built in order to check the grid independence of the results.

It is worth mentioning that the mesh is not affected by the features of the simulated fire scenario. In fact, the type of fire exposure (in terms of target positioning and fire intensity) only affects the definition of the boundary conditions for the 2D CFD model but does not affect the calculation domain.

\section{Definition of the case studies}

In order to assess the effectiveness of the modeling approach, a simulation reproducing the experimental conditions described in Section 2 was run and the results were compared with experimental measurements of wall and fluid temperature and pressure. The tank was filled with LPG at an absolute pressure of $7 \mathrm{bar}$; at the beginning of the test, the filling fraction was $15 \%$.

Once the model was validated (see Section 5.1 for more details), thus demonstrating its reliability in reproducing the pressurization and heat up observed in the test imposing the same experimental incoming heat flux as boundary condition, different case studies were defined in order to perform a sensitivity analysis on the main parameters affecting the vessel response to forest fires. In particular, case-studies were considered to assess the influence of the following parameters:

\section{- Filling level effect on the pressurization rate}

Three filling levels were defined in order to contemplate (i) the low filling level condition of the experimental test (15\%), (ii) a high filling level (90\%) and (iii) an intermediate situation (50\%).

\section{- Different tank geometries}

Two tank types were considered: beside the geometry adopted in the actual experimental tests, the maximum capacity of LPG bulk storage for civil use was adopted $\left(9 \mathrm{~m}^{3}\right)$ (HSE-Health Safety Executive, 2009).

- Different forest fire scenarios involving the same tank

Fire conditions were derived considering the two fire scenarios defined in Table 1. Both are asymmetric (i.e., tank exposed on one side). However, in cases in which the tank is remotely located in the forest, the fire may also possibly surround the tank. Hence, in order to investigate this situation, symmetric fire exposure was also considered. Symmetry is intended here with respect to a vertical plane cutting the tank in the axial direction.

Based on the aforementioned considerations, Table 3 summarizes the set-up specifications adopted to define the case-studies. Each of them was identified according to the following labelling system: the first letter refers to the tank type (A for the $2.30 \mathrm{~m}^{3}$ tank and B for the $9.00 \mathrm{~m}^{3}$ tank); the second letter indicates the filling level, e.g. L (low) $=15 \%, M$ ( medium $)=50 \%$ and $\mathrm{H}$ (high) $=90 \%$; the numbers 1 and 2 identify the first and the second fire scenario respectively. The case-studies in which a symmetric fire condition was imposed are identified by "S" added at the end of the tag. 
Table 3 - Summary and definition of the case studies. Table entries without labelling correspond to not simulated cases.

\begin{tabular}{|c|c|c|c|c|c|c|c|}
\hline \multirow[t]{2}{*}{ Fire characteristics } & & \multicolumn{3}{|c|}{$\begin{array}{c}\text { Tank type } 1 \\
\text { Volume } 2300 \mathrm{~L} \\
\text { Diameter } 1 \mathrm{~m} \\
\text { Thickness } 6 \mathrm{~mm} \\
\text { Filling level }\end{array}$} & \multicolumn{3}{|c|}{$\begin{array}{c}\text { Tank type } 2 \\
\text { Volume } 9000 \mathrm{~L} \\
\text { Diameter } 1.6 \mathrm{~m} \\
\text { Thickness } 14 \mathrm{~mm} \\
\text { Filling level }\end{array}$} \\
\hline & & $15 \%$ & $50 \%$ & $90 \%$ & $15 \%$ & $50 \%$ & $90 \%$ \\
\hline $\begin{array}{l}\text { Fire condition } 1 \text { : } \\
\text { Fire height } 40 \mathrm{~m} \\
\text { Fire length } 100 \mathrm{~m} \\
\text { Average emissive power } 90 \mathrm{~kW} / \mathrm{m}^{2} \\
\text { Distance from the tank } 50 \mathrm{~m} \\
\text { Maximum incident radiation } 24 \mathrm{~kW} / \mathrm{m}^{2} \\
\text { Total heat flux received } 84 \mathrm{~kW}\end{array}$ & Asymmetric & AL1_S & AM1 & AH1 & BL1 & BM1 & BH1 \\
\hline $\begin{array}{l}\text { Fire condition } 2 \text { : } \\
\text { Fire height } 40 \mathrm{~m} \\
\text { Fire length } 100 \mathrm{~m} \\
\text { Average emissive power } 68 \mathrm{~kW} / \mathrm{m}^{2} \\
\text { Distance from the tank } 28 \mathrm{~m} \\
\text { Maximum incident radiation } 41 \mathrm{~kW} / \mathrm{m}^{2} \\
\text { Total heat flux received } 133 \mathrm{~kW}\end{array}$ & Asymmetric & AL2_S & - & $\mathrm{AH} 2$ & BL2_S & - & BH2 \\
\hline
\end{tabular}

In order to determine the maximum simulation time (namely, $\tau_{0}$ ), the preliminary considerations reported in (Billaud et al., 2011; Heymes et al., 2013b) were taken into account. In fact, the time during which an LPG tank is affected by wildfire radiation depends on several factors, such as wind velocity, spreading rate, geometry, canopy massiveness, ambient temperature and humidity. According to (Heymes et al., $2013 b$ ), a conservative exposure time of $\tau_{0}=1200 \mathrm{~s}$ was selected as maximum reference time for the simulation of the case studies. However, in the cases where the relative pressure inside the tank reached the opening pressure of the PRV (19.6 barg), the simulation was stopped at the PRV opening time.

\section{Results and discussion}

\subsection{Experimental results and 2D CFD model validation}

In this section, the results obtained with the 2D CFD simulation of the fire test described in Section 2 are compared with the experimental data.

Fig. 4 shows the comparison among the experimental and predicted pressure, while Table 4 reports a summary of the absolute and relative error associated with the 2D CFD model predictions. As shown in Fig. 4, the pressurization curve recorded during the test (red line) is well reproduced by the 2D CFD simulation (blue line). The two curves match almost perfectly for the first $12 \mathrm{~min}$. Then, the predicted pressure starts deviating from the measured one.

However, the relative error remains always below 3\%, as shown in Table 4. Comparing the solid blue line and the green dashed line, obtained running the simulation using the finer mesh, it may be concluded that the predicted pressure rise is grid independent. In fact, the two curves are almost superimposed, with a maximum difference of $0.68 \%(8.3 \mathrm{kPa})$.

The results obtained are not significantly influenced by the time-step. In fact, the relative deviation between the pressure obtained using $5 \mathrm{~ms}$ and the halved time step $(2.5 \mathrm{~ms})$ was always lower than $1.2 \%$; hence the time-step of $5 \mathrm{~ms}$ was kept for the assessment of the case-studies.
Fig. 5 shows the comparison between the experimental measurements and 2D CFD predictions in terms of temperature profile at the external wall (Fig. 5a-c) and fluid temperatures on the vertical center line of the tank (Fig. 5d-f), taken at different times. External wall temperatures are plotted in the correspondent charts as a function of the $\theta$ coordinate (see Fig. $5 \mathrm{a}-\mathrm{c}$ ). Tank lading temperatures are plotted as a function of vertical coordinate y (see Fig. $5 d-f$ ). The fire wall is on the right side of the vessel (in correspondence of $\theta=0^{\circ}$ ). The liquid domain position is indicated by the shaded area. Table 5 summarizes the analysis of absolute and relative error associated with 2D CFD temperature predictions.

Temperature values obtained from 2D CFD predictions are generally in good agreement with the experimental data obtained from the thermocouples installed on the external wall (see Fig. $5 \mathrm{a}-\mathrm{c}$ ). Overpredictions are obtained in the portion of the tank surface exposed to higher heat flux values (e.g., on the side facing the fire wall, see the sketch in Fig. 1 for the experimental set up layout). The difference with the experimental results increases with time, with maximum discrepancies in the portion of tank wall between $\theta=10^{\circ}$ and $\theta=50^{\circ}$. This clearly appears from Table 5 , where both the relative and absolute errors relative to thermocouples $T_{B}$ and $T_{C}$ appear to be the highest among the wall thermocouples.

It should be considered that the variation of the flame shape, especially in the upper part of the fire wall, introduces a degree of uncertainty in the boundary condition. Therefore, despite the effort in the definition of the boundary condition, limited discrepancies between experimental and 2D CFD results should be expected.

Fig. 6 confirms that neglecting the convective contribution of the air surrounding the tank leads to overpredictions of temperatures. The dashed lines were obtained considering a fixed heat transfer coefficient of $5 \mathrm{~W} /\left(\mathrm{m}^{2} \mathrm{~K}\right)$ between the external wall and the surrounding air, while the solid line is associated with the results obtained without natural convection. As expected, a temperature decrement is obtained both in the liquid and vapor phases when considering the natural convection, as shown in Fig. $6 \mathrm{~b}$ for 20 min simulation time. This decrement is of about $10-15 \mathrm{~K}$ and relatively small compared with the overprediction of the wall temperature showed for instance in Fig. $5 \mathrm{c}(\approx 50-70 \mathrm{~K}$ overprediction). 


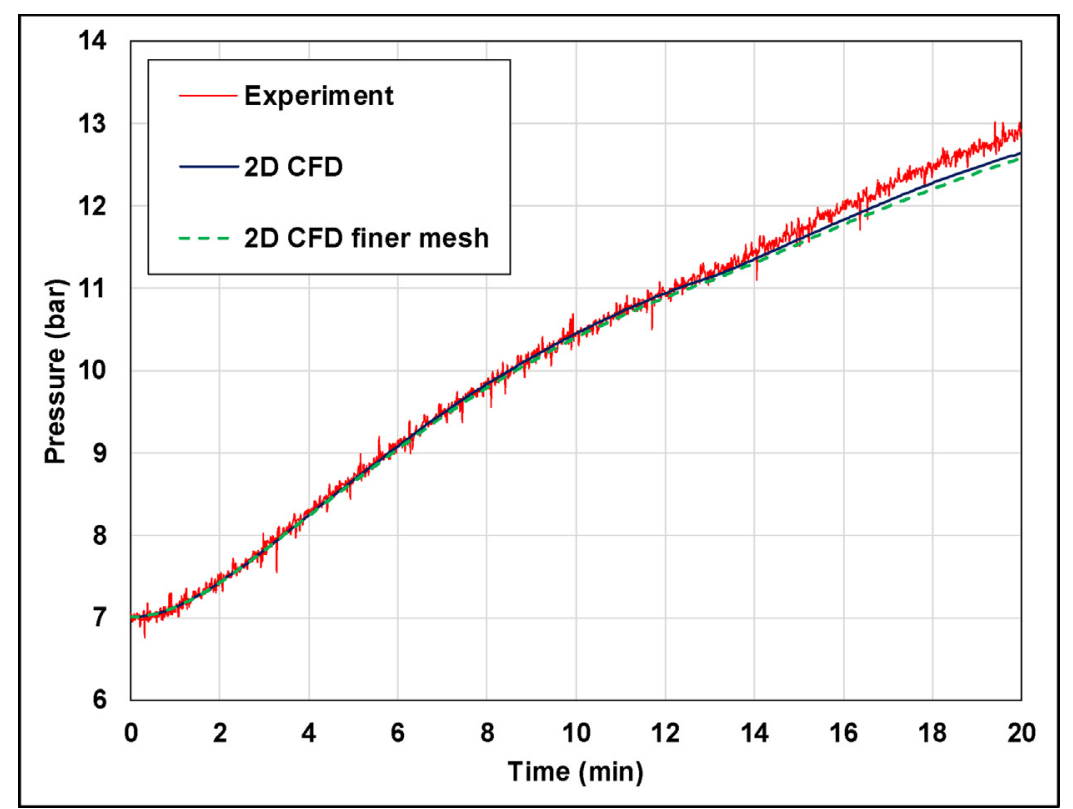

Fig. 4 - Comparison among the measured pressure and the pressure obtained by the 2D CFD simulations. The simulation was set up with the mesh adopted in the case studies and with a finer mesh (see Section 3.4). (For interpretation of the references to color in the text, the reader is referred to the web version of this article.)

Table 4 - Comparison between experimental pressure $\left(P_{\text {exp }}\right)$ and 2D CFD model results $\left(P_{\text {CFD }}\right)$ : absolute error $\left(\chi_{\text {abs }}\right)$ and relative error $\left(\chi_{\text {abs }}\right)$. Max $=$ maximum value; $\min =$ minimum value.

\begin{tabular}{|c|c|c|c|c|}
\hline \multicolumn{3}{|c|}{$\begin{array}{l}\text { Absolute error, } \chi_{\text {abs }} \text { (bar) } \\
\chi_{a b s}=\left|P_{C F D}-P_{\text {exp }}\right|\end{array}$} & \multicolumn{2}{|c|}{$\begin{array}{l}\text { Relative error } \chi_{\text {rel }}(\%) \\
\chi_{\text {rel }}=\frac{P_{\text {CFD }}-P_{\text {exp }}}{P_{\exp }} \times 100\end{array}$} \\
\hline Max & Min & Average & Max & Min \\
\hline 0.3 & 0.0 & 0.1 & $1.3 \%$ & $-2.4 \%$ \\
\hline
\end{tabular}

Table 5 - Comparison between experimental temperatures ( $\left.\mathrm{T}_{\mathrm{exp}}\right)$ and 2D GFD model results ( $\left.\mathrm{T}_{\mathrm{CFD}}\right)$ : absolute error $\left(\chi_{\mathrm{abs}}\right)$ and relative error $\left(\chi_{\mathrm{abs}}\right)$ for each thermocouple. $\mathrm{Max}=$ maximum value; $\min =\operatorname{minimum}$ value. For thermocouple positioning and labeling, refer to the sketch shown in the table.

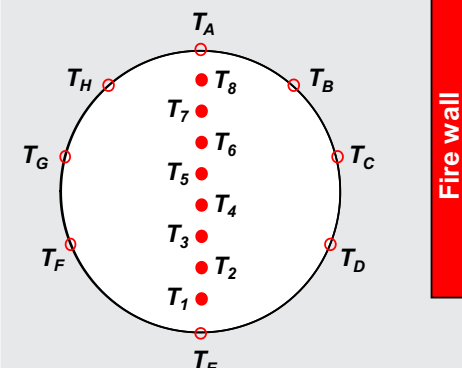

\begin{tabular}{|c|c|c|c|c|}
\hline \multicolumn{3}{|c|}{$\begin{array}{l}\text { Absolute error, } \chi_{\text {abs }}(\mathrm{K}) \\
\chi_{a b s}=\left|T_{\mathrm{CFD}}-\mathrm{T}_{\text {exp }}\right|\end{array}$} & \multicolumn{2}{|c|}{$\begin{array}{l}\text { Relative error, } \chi_{\text {rel }}(\%) \\
\chi_{\text {rel }}=\frac{T_{\text {CFD }}-T_{\text {exp }}}{T_{\text {exp }}} \times 100\end{array}$} \\
\hline Max & Min & Average & Max & Min \\
\hline 29.9 & 0.1 & 17.7 & $5.7 \%$ & $-8.4 \%$ \\
\hline 70.3 & 0.2 & 30.3 & $12.6 \%$ & $-0.3 \%$ \\
\hline 86.1 & 1.4 & 48.4 & $15.8 \%$ & $0.5 \%$ \\
\hline 36.0 & 0.5 & 26.9 & $8.0 \%$ & $-1.0 \%$ \\
\hline 9.0 & 0.0 & 5.4 & $0.8 \%$ & $-3.0 \%$ \\
\hline 11.5 & 0.0 & 3.6 & $3.4 \%$ & $-0.8 \%$ \\
\hline 40.7 & 0.0 & 13.8 & $10.5 \%$ & $-0.4 \%$ \\
\hline 26.2 & 0.3 & 9.3 & $6.4 \%$ & $-3.9 \%$ \\
\hline 3.5 & 0.3 & 1.5 & $1.2 \%$ & $0.1 \%$ \\
\hline 37.1 & 0.1 & 20.9 & $0.9 \%$ & $-10.7 \%$ \\
\hline 6.0 & 0.1 & 3.1 & $1.8 \%$ & $-1.6 \%$ \\
\hline 39.5 & 2.0 & 19.7 & $9.4 \%$ & $0.7 \%$ \\
\hline 54.0 & 1.9 & 26.4 & $12.3 \%$ & $0.7 \%$ \\
\hline 58.6 & 2.0 & 29.2 & $12.9 \%$ & $0.7 \%$ \\
\hline 65.5 & 1.9 & 31.9 & $14.1 \%$ & $0.7 \%$ \\
\hline 71.0 & 1.8 & 33.4 & $14.9 \%$ & $0.6 \%$ \\
\hline
\end{tabular}


a)

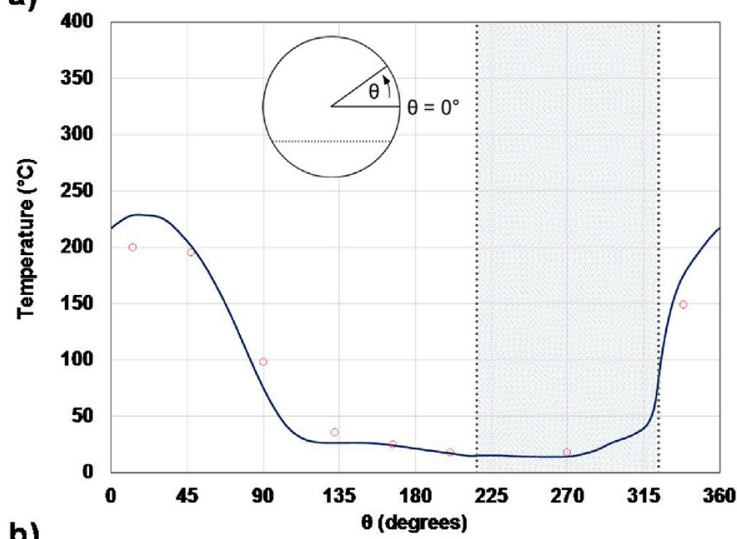

b)

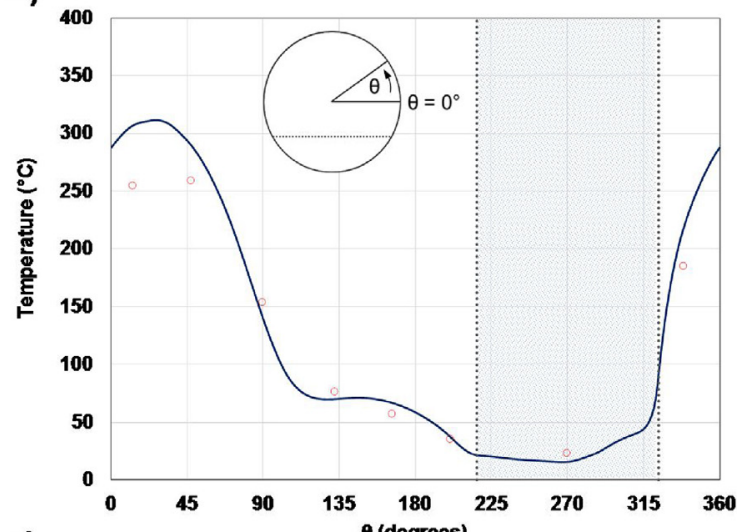

c)

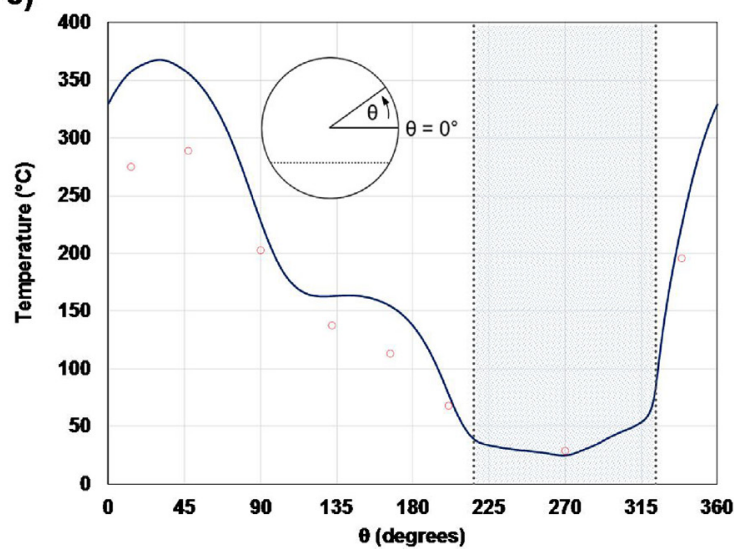

d)

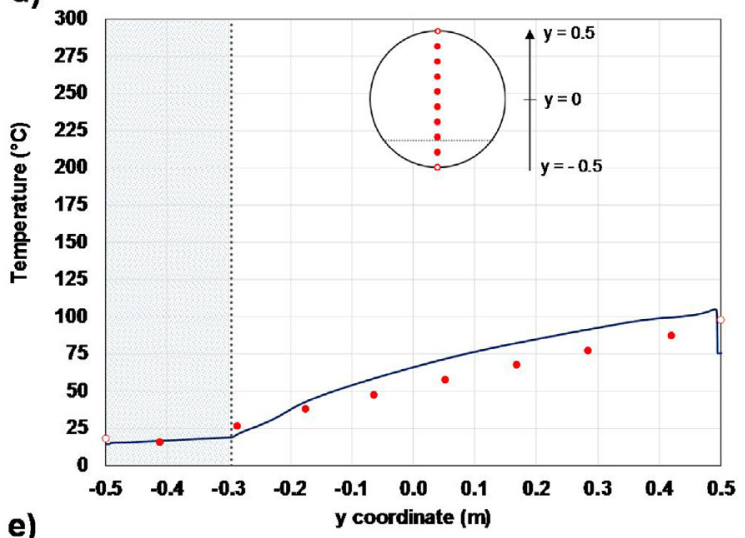

e)

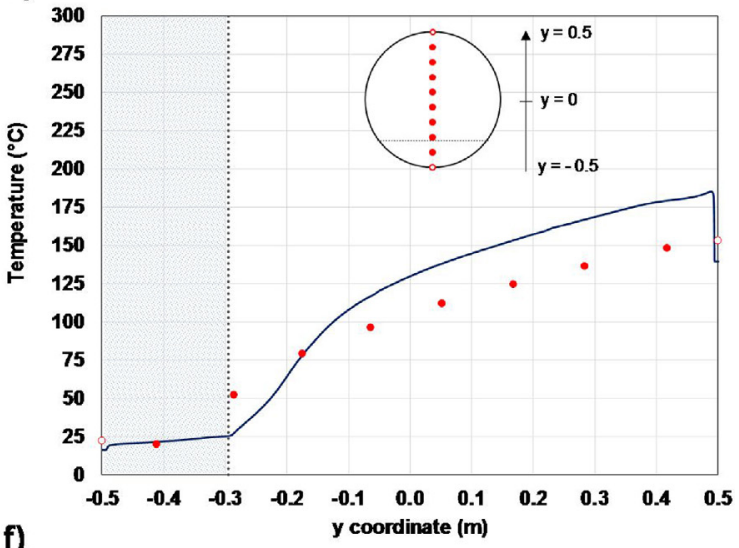

f)

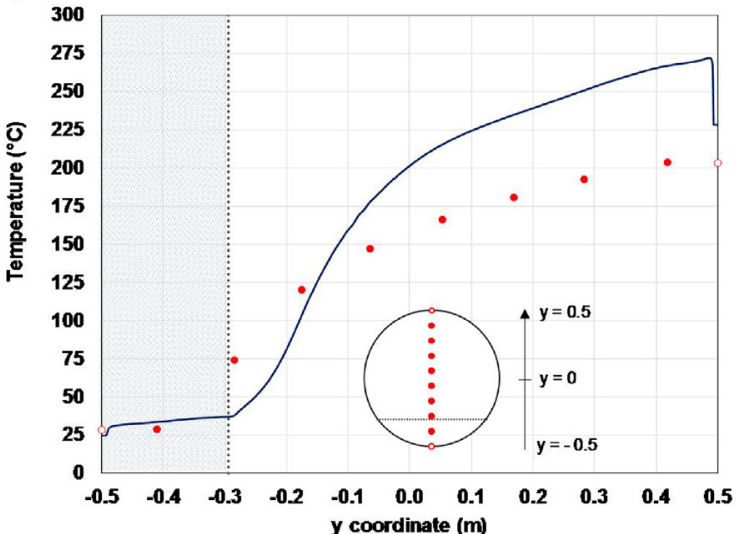

Fig. 5 - Temperature profiles at different times: on the outer wall at $5 \mathrm{~min}$ (a), $10 \mathrm{~min}$ (b), and $20 \mathrm{~min}$ (c) function of the angular coordinate $\theta$; on the tank vertical axis y at $5 \mathrm{~min}$ (d), $10 \mathrm{~min}$ (e) and $20 \mathrm{~min}(\mathrm{f})$. The shaded area represents the shell portion in contact with the liquid (a-c; $216^{\circ}<\theta<324^{\circ}$ ) and the liquid domain (d-f; $-0.5<\mathrm{y}<-0.295 \mathrm{~m}$ ). The fire wall is on the right side of the vessel (where $\theta=0^{\circ}$ ).

Since the adopted heat transfer coefficient is uniform and constant during fire exposure, the decrement in the temperature estimated with natural convection affects all the portions of the tank, thus driving the lower pressurization rate shown in Fig. $6 \mathrm{a}$ and leading to non-conservative estimations, which are however always lower than 0.5 bar underprediction and only in the final part of the test (e.g., after 14 min, Fig. 6a).

Therefore, it may be concluded that natural convection has a limited influence on the final simulation results, and the conservative choice of neglecting this contribution allows the reduction in the uncertainty associated with input parameters in the 2D CFD model.

With respect to the tank lading, it appears that the temperature in the liquid phase is well reproduced, whit a maximum relative error and absolute error of $1.2 \%$ and $3.5 \mathrm{~K}$ respectively (see Table 5). On the other hand, the thermal profile measured in the vapor space is generally overestimated by the 2D CFD simulation. Table 5 shows that, apart from thermocouples $\mathrm{T}_{1}$, $T_{2}$ and $T_{3}$, the absolute and relative errors increase with the vertical coordinate.

A possible explanation for the overprediction of the temperature in the upper part of the tank is obtained considering the flow pattern represented in Fig. 7a. A recirculation cell forms close to the top right part of the tank (the side exposed to the fire), while the bulk of the vapor is almost motionless Fig. 7b. On the right side, the velocity field is directed upwards. On the contrary, on the left side, where the vapor is cooled down by the cold wall, the flow is directed towards the bottom of the tank. Therefore, the overestimation of the temperature in the upper part could be a consequence of the fact that the model is overpredicting the temperature in the hottest region of the wall (as discussed above, see Fig. $5 \mathrm{a}-\mathrm{c}$ ). Thus, in the 
a)

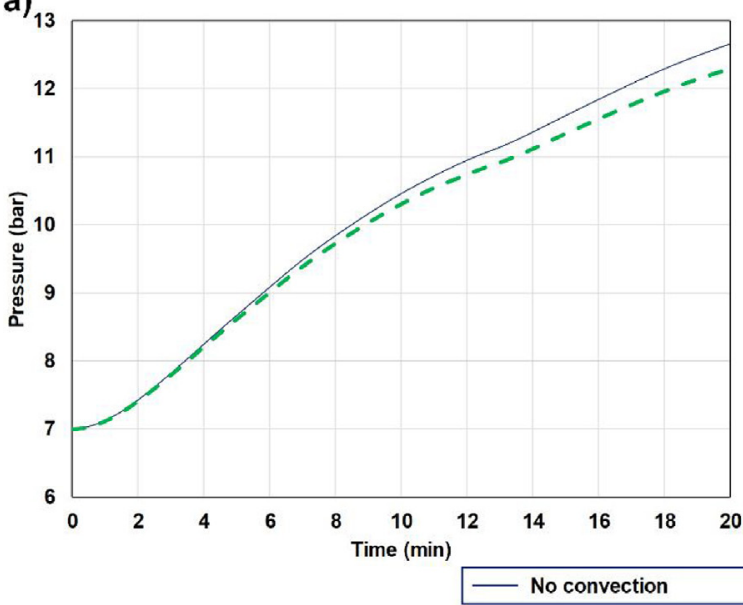

b)

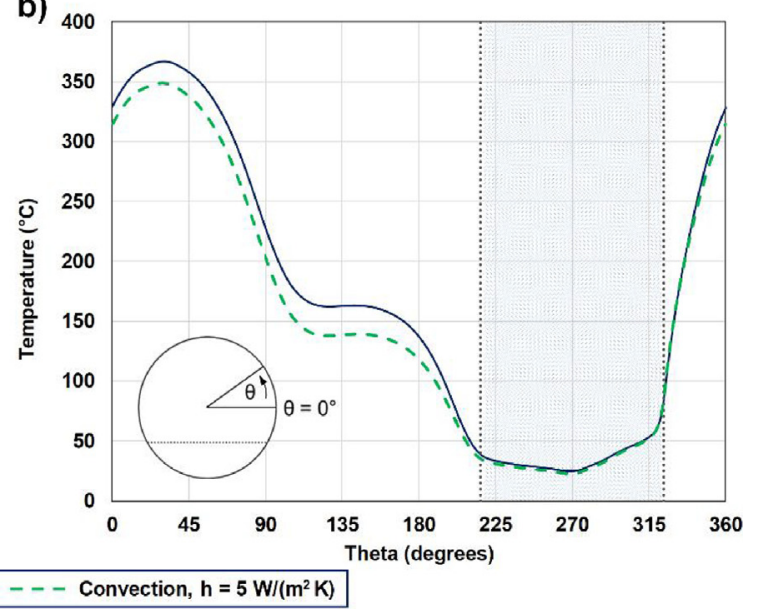

Fig. 6 - Comparison of pressurization curve (a) and wall temperature profile after 20 min (b) neglecting external convection (solid line) or assuming a heat transfer coefficient of $5 \mathrm{~W} /\left(\mathrm{m}^{2} \mathrm{~K}\right)$ (dashed line). The shaded area represents the shell portion in contact with the liquid $\left(216^{\circ}<\theta<324^{\circ}\right)$.
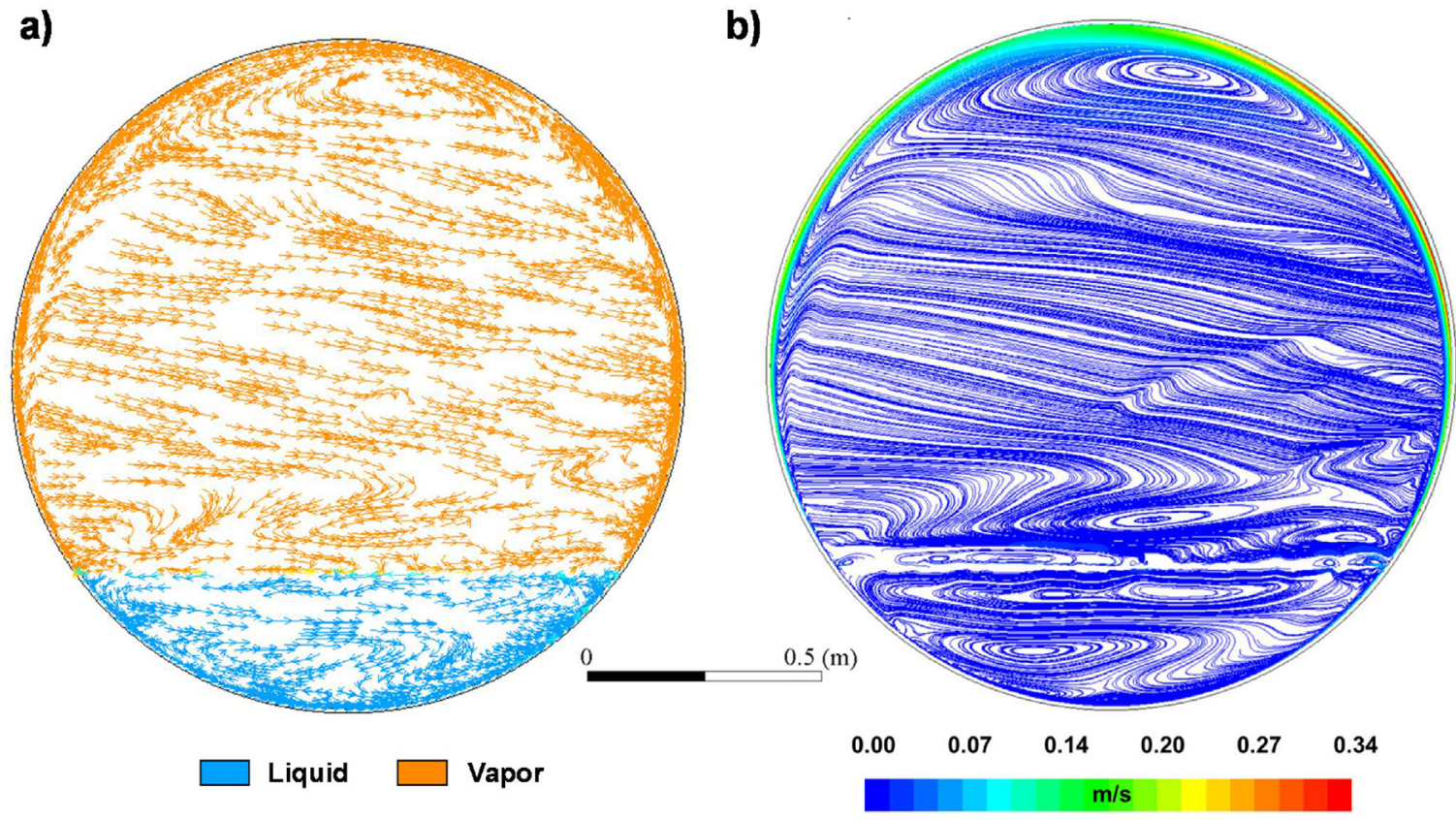

Fig. 7 - Predicted pahtlines in the vapor (orange) and in the liquid (light blue) phases (a) and pathlines colored according to the velocity magnityte, in $\mathrm{m} / \mathrm{s}$ (b) for the validation case $10 \mathrm{~min}$ after fire start. (For interpretation of the references to color in this figure legend, the reader is referred to the web version of this article.)

simulation, the upper part of the tank is fed by a vapor flow warmer than that actually present in the real vessel.

Another critical result obtained from the simulations is the difference in the temperatures of the region immediately above the liquid surface, where complex interaction phenomena between the two phases are probably not captured by 2D CFD. Here, the temperature is overestimated, with a maximum discrepancy of $37 \mathrm{~K}$ between the model end the measurements (see thermocouple $\mathrm{T}_{2}$ in Table 5) and a relative error of $-10.7 \%$.

From these results, it is possible to conclude that the pressure build-up mainly depends on the liquid temperature, confirming the outcomes of several previous studies (Birk and Cunningham, 1994; Hadjisophocleous et al., 1990; Shi et al., 2012).

It is work mentioning that an inherent limitation of the present modeling approach is related to the choice of conducting 2D CFD simulations instead of a 3D analysis. The choice was driven by the minimization of computational efforts and corroborated by the fact that end effects may be attenuated in case of high length-to-diameter ratios, such as in the case of the cylindrical tanks of interest in the present study. However, the choice of a 2D domain is an approximation and the tank ends may alter the boundary layer and thus the consequent heat-up and pressurization rate associated with complex recirculating phenomena. In order to investigate more in detail these effects, possible future developments may be related to the 3D implementation of the present model, but with a relevant increment of computational time efforts.

\subsection{Analysis of the case studies}

In this section, the results obtained from the simulation of the case studies previously defined are presented and discussed. Fig. $8 a$ and $b$ show the pressure rise curves for the small $\left(2.3 \mathrm{~m}^{3}\right)$ and large $\left(9 \mathrm{~m}^{3}\right)$ capacity tank respectively. Considering the small capacity tank (Fig. 8a) under fire condition 1 

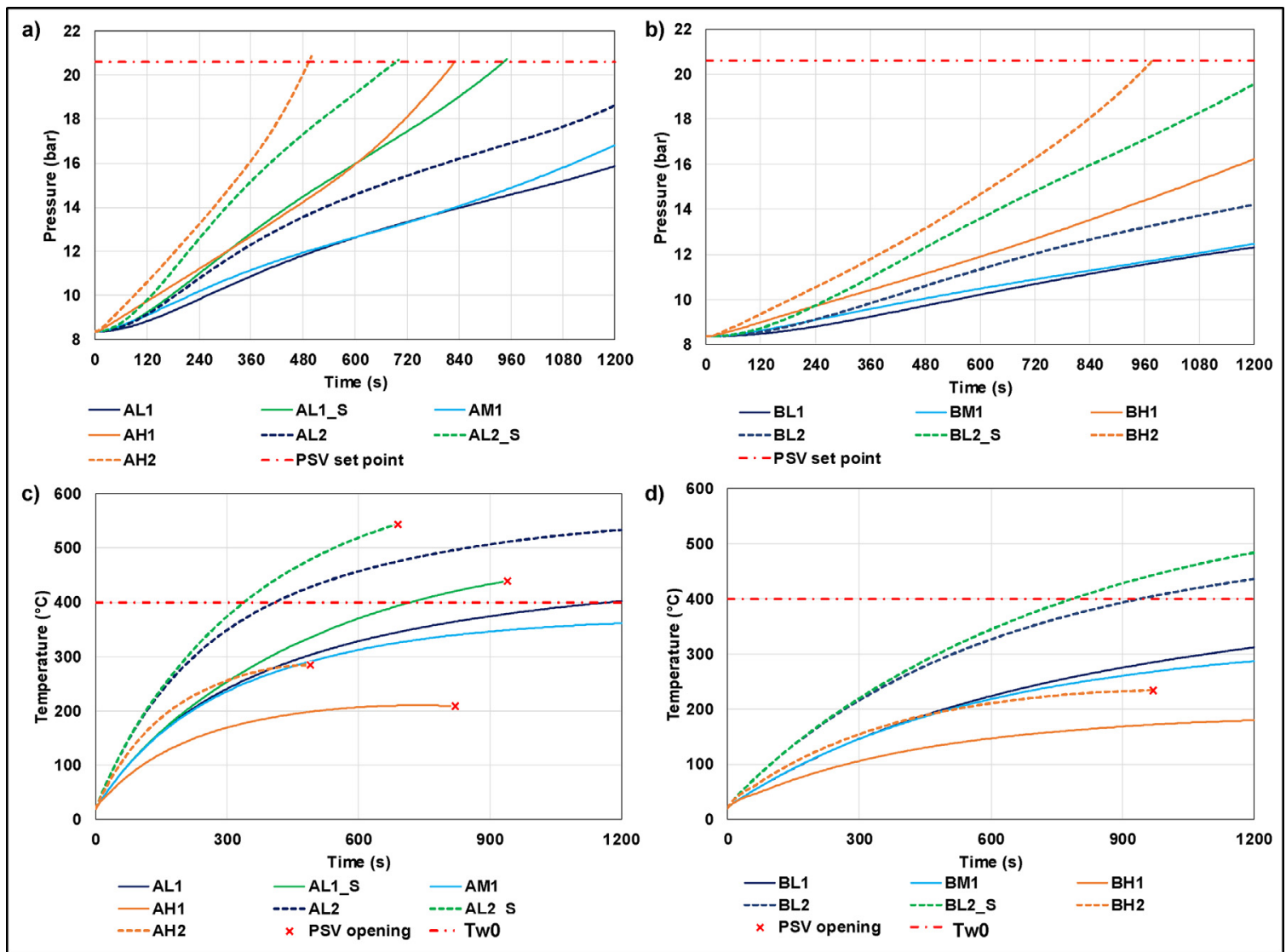

Fig. 8 - Results of the 2D CFD simulations of the case studies: pressure rise curve for the small capacity tank (a) and large capacity tank (b); maximum external wall temperature for small capacity tank (c) and large capacity tank (d). Limit condition for pressure opening ("PSV opening") and for wall temperature ("T $\mathrm{wo}_{0}$ ") are reported. See Table 3 for the explanation of tags identifying the conditions of the different simulation runs.

(asymmetric), no substantial difference is found between the low (AL1) and the medium (AM1) filling degree cases. For both of them, the PSV set point (20.6 barg) is not reached during the simulations. On the contrary, when the liquid level rises up to $90 \%$ of tank volume (AH1), the pressurization becomes considerably faster, leading to the opening of the PSV after 829s. As expected, the exposure to a more severe fire scenario leads to an acceleration of the pressure build-up. In the high filling level case (AH2), for instance, the PSV opening occurs $335 \mathrm{~s}$ earlier. The same is valid for the cases in which both sides of the tank are exposed to a fire attack (AL1_S and AL2_S).

A similar behavior is found for the large capacity tank (Fig. 8b). In this case, however, due the larger thermal inertia, the pressure rise is slower, and the PSV set point is reached only for the high filling level case under fire condition 2 (BH2).

The results obtained, in line with experimental and numerical outcomes obtained in previous studies (Aydemir et al., 1988; Birk, 1995; Moodie, 1988), show that the pressurization rate of vessels exposed to fire is affected by the filling level. In the case of high filling levels the pressurization rate is faster with respect to low filling level conditions.

Fig. $8 \mathrm{c}$ and $\mathrm{d}$ show the maximum temperature reached at the outer wall as a function of time for the $2.3 \mathrm{~m}^{3}$ and $9.0 \mathrm{~m}^{3}$ tanks respectively. The line labeled as " $\mathrm{T}_{\mathrm{w} 0}$ " indicates a threshold limit for the wall temperature, which is $400^{\circ} \mathrm{C}$. This value is indicated in the literature as a reference point for thermal weakening (Lees, 1996; SCI-Steel Construction Institute, 1992). In particular, at this temperature, the A48P1 steel experiences a $35 \%$ reduction of the yield strength $\left(R_{p 0.2}\right)$ with respect to its value at $25^{\circ} \mathrm{C}$ (CEN - European Committee for
Standardization, 1998). It is worth noticing how, in the high filling level cases, the maximum wall temperature remains well below $\mathrm{T}_{\mathrm{w} 0}$. On the other hand, in the low filling level cases, this critical value is often exceeded. This represents a critical aspect since the presence of hot spots may lead to plastic deformation and thinning of the wall, compromising the tank integrity before the opening of the PSV, such as in the case of insulated tanks exposed to fire in presence of defective protections (Scarponi et al., 2016). The AL2_S case, where red line is crossed well before the PSV opening (about $5 \mathrm{~min}$ ), evidence how critical may become such scenarios.

The vessel failure probability increases not only with the temperature, but also with the extension of the weakened area. Fig. 9a shows the wall temperature profile as a function of the $\theta$ angle for different instants of time for the case labelled as AL1 (2.3 $\mathrm{m}^{3}$ tank, 15\% filling, fire scenario 1$)$. It can be noticed how the portion of the wall falling beyond the threshold $\mathrm{T}_{\mathrm{w}}$ increases with time. For the symmetric case (Fig. 9b), the weakened zone is even more extended, due to the exposure to fire of both sides of the tank. On the other hand, when the high filling case is considered (Fig. 9c), the cooling effect of the liquid keeps the wall temperature relatively low, limiting the loss of mechanical strength. Finally, in Fig. 9d it is possible to evaluate the effect of the higher thermal inertia of the $9 \mathrm{~m}^{3}$ tank. In this case, the wall temperatures remain considerably lower compared with those registered in the $2.3 \mathrm{~m}^{3}$ case.

For what concerns the analysis of the tank lading behavior, Fig. 10 shows the temperature contour and the path line plots for a symmetric (AL1) and an asymmetric (AL1_S) fire condition taken at 360s. As expected, the temperatures are higher in the 


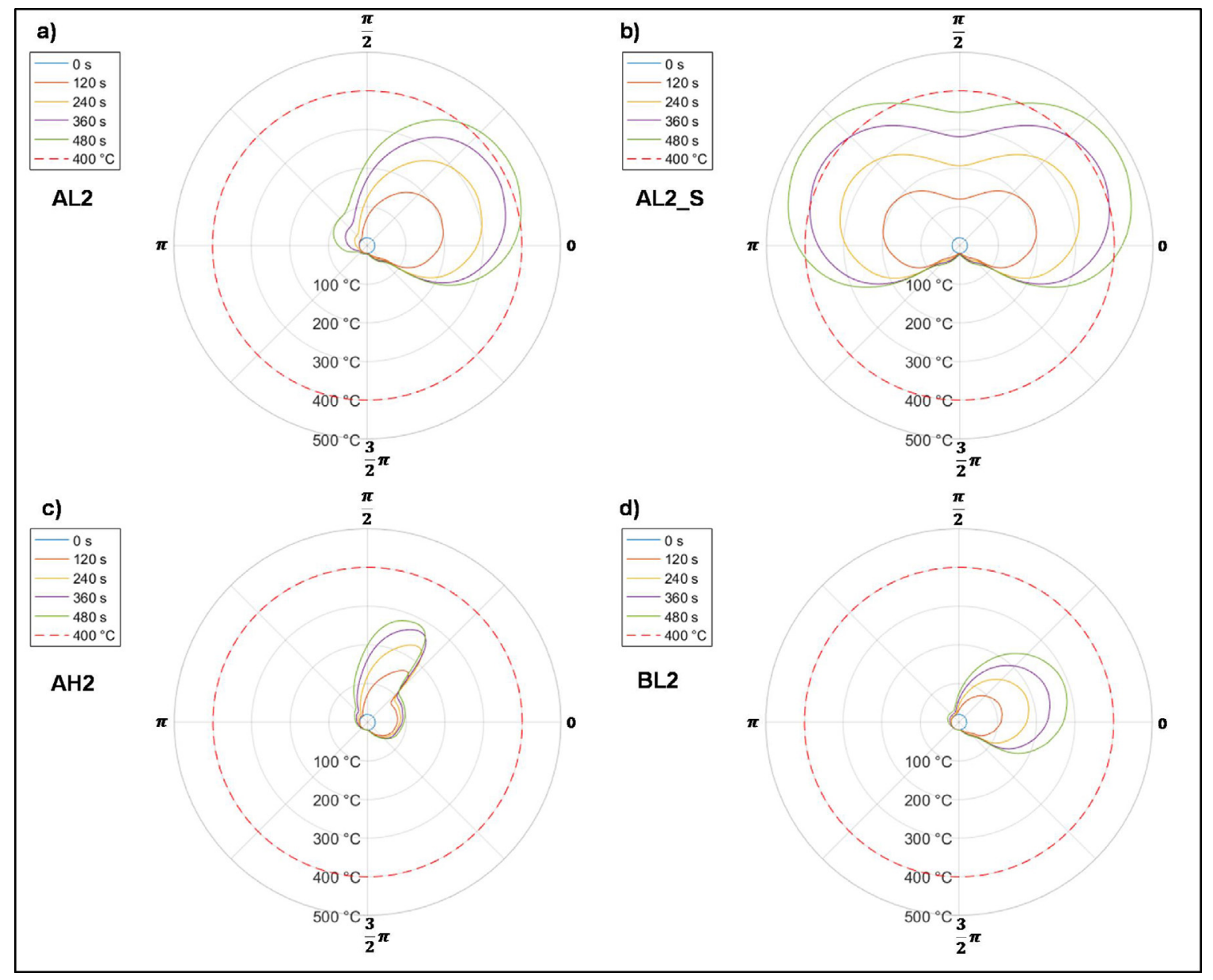

Fig. 9 - Radar plot of the outer wall temperature function of the angular coordinate $\theta$ at different instant of time for the cases ALD (a), AL2_S (b), AH2 (c) and BL2 (d). The angle coordinate is schematized in Fig. $1 \mathrm{~b}$.

latter case, due to the heating of both sides of the tank. It is worth noticing that in both cases the temperature is almost constant in the horizontal direction with the exception of a small region near the wall (Fig. 10a and b), both in symmetric and asymmetric cases. On the contrary, Fig. 10c and d show a clear difference in the flow patterns. In the first case, the path lines depict a strongly asymmetric flow field, both in the liquid and in the vapor phases. In the second case, even though a perfect symmetry is not verified, it is possible to recognize a symmetry among the two vertical halves of the tank.

Finally, it is worth noting that the bulk of the fluid is almost motionless. This explains the strong thermal stratification highlighted in the temperature contour plots.

\subsection{Discussion}

The analysis of the case studies allowed quantifying the effect of different fire and geometrical conditions on the pressurization rate and thermal weakening of target exposed to forest fires. In order to assess failure conditions induced by the fire, either thermal or mechanical evaluations are needed. However, the detailed stress analysis of the fired vessel (e.g., see Birk, 1989; Manu et al., 2009; Rebec et al., 2016 for more details), is out of the scope of the present study. Therefore, in order to obtain at least preliminary indications on the possible damage state on a target vessel, a specific simplified approach was defined in the present study, in order to estimate the extent of the thermal weakening induced by a forest fire and the poten- tial severity of the scenarios following the possible rupture induced by the fire.

With this purpose, three key performance indicators (KPIs) were defined. The first KPI was termed the Weakened Surface Index (WSI), and was defined as follows:

$\mathrm{WSI}=\mathrm{S}_{a} / \mathrm{S}_{\mathrm{t}}$

where $S_{a}$ is the surface area in which the temperature is higher than $400^{\circ} \mathrm{C}$ and $\mathrm{S}_{\mathrm{t}}$ is total surface area of the tank (excluding the elliptical ends). A second KPI was defined as the Weakening Time Index (WTI), defined as follows:

$\mathrm{WTI}=\tau / \tau_{0}$

where $\tau$ is the time lapse during which the tank wall exceeds the reference temperature $\mathrm{T}_{\mathrm{w} 0}$ before the PSV opens or until the end of the simulation, if the PSV opening conditions are not reached, and $\tau_{0}$ is a reference time. This parameter was derived based on the quantitative assessment provided by (Billaud et al., 2011), in which the heat flux impacting a house located at $50 \mathrm{~m}$ from a spreading wildfire was estimated, showing that the target could be impacted for $600 \mathrm{~s}$ with variable intensity. This value was then doubled, according to the indications shown by (Heymes et al., 2013b), obtaining a conservative reference time (e.g., $\tau_{0}=1200 \mathrm{~s}$ ).

An important aspect that affects the thermal response of vessels during the heat-up in the different configurations considered in the case-studies is that a different amount of energy 


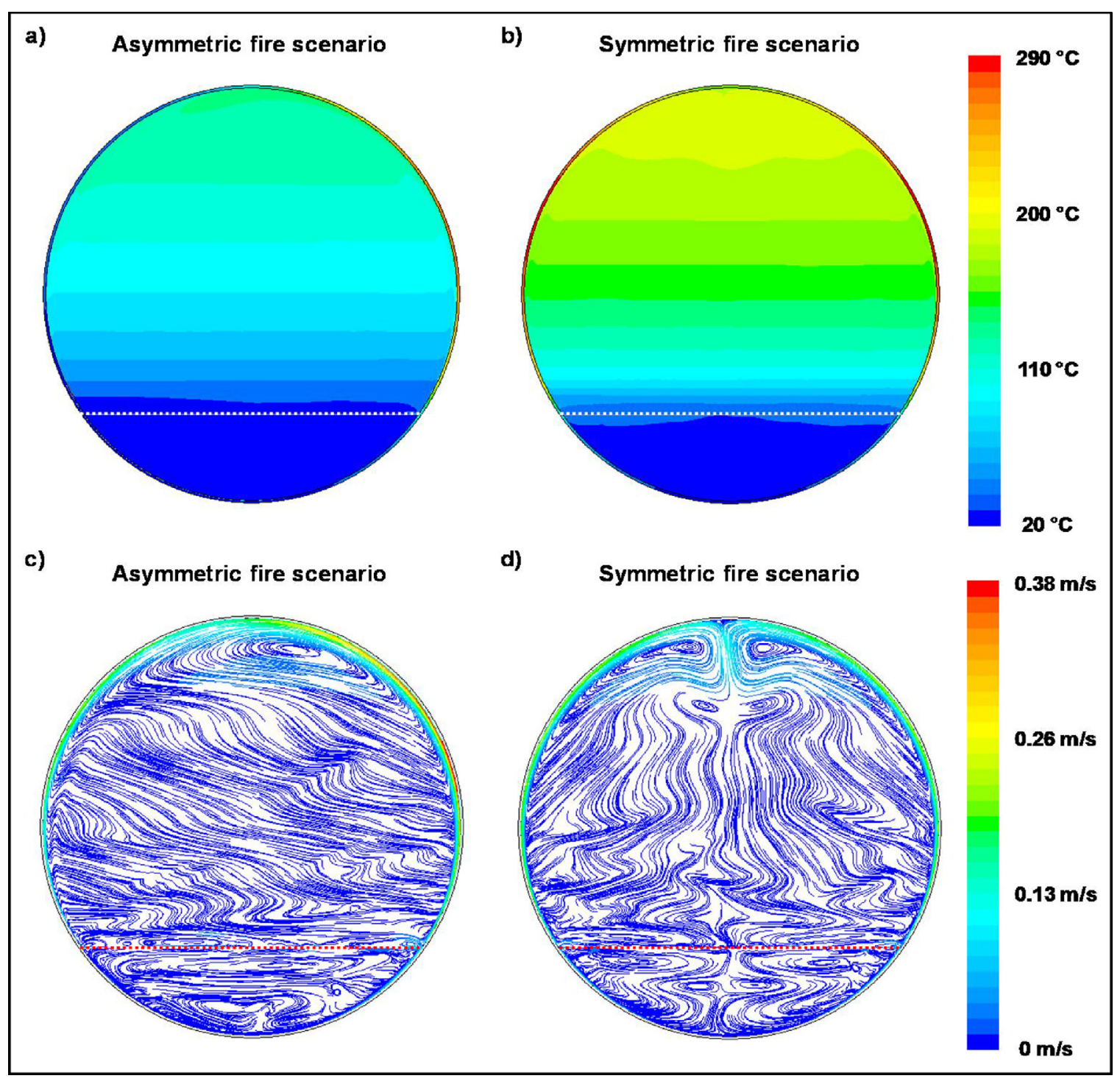

Fig. 10 - Comparison among asymmetric and symmetric fire exposure conditions: temperature contour plot for case AL1 (a) and case AL1_S (b); path line plot for case AL1 (c) and AL1_S (d). 2D CFD results were extracted at $360 \mathrm{~s}$ in both cases. Dotted lines indicate the initial liquid level. Key to conditions used for the two case-studies is reported in Table 3.

is introduced in each system depending on the geometry and on the filling level. This is due to the fact that a distant source radiation was imposed on the outer surface of the vessel, that is different in each case-study. In order to provide a simplified assessment of effect of the different geometries and filling level values on the heat-up of the lading, the energy accumulation was estimated in in each case study. The heat flux received by the liquid during the simulation was integrated, following the approach shown in (Landucci et al., 2016). The accumulated energy (namely, U) was defined as the third reference KPI for the analysis of simulation results. For a generic time, $t, U(t)$ is evaluated as follows:

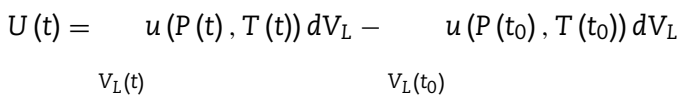

where $u$ is the internal energy per unit volume, $P$ is the pressure, $T$ is the temperature, $V_{L}$ is the liquid volume, and $t_{0}$ is the initial simulation time. The internal energy $u$ is directly provided by the solver from the solution of the energy conservation equation shown in Table 2 (ANSYS inc, 2012).
Fig. 11 summarizes the values calculated for the KPIs defined in the present study. Fig. 11a shows the comparison among the indexes related to thermal weakening (WTI, WSI) and Fig. 11b shows the accumulated energy (U).

WSI was calculated after 600 (green bars) and, where possible, after $900 \mathrm{~s}$ (blue bars) in order to show the trend with respect to time of the weakening of the vessel. No bar is showed when the KPI values are zero (i.e., the temperature is under $400^{\circ} \mathrm{C}$ at the time considered for index calculation). The values of WSI indicate that, in some situations, the weakened area is quite extended, from about 0.2 in the case labelled as AL2 to more than 0.5 in the AL2_S case.

Considering the results obtained for the WTI (red bars), it appears that the condition of mechanical strength reduction may last, in some cases, for a long time before the before PSV intervention (or the end of the fire). According to the WTI, the AL2 case results as the most critical one. In fact, in this case the maximum temperature of the wall is higher than $400^{\circ} \mathrm{C}$ for $2 / 3$ of the total simulated time. More in general, both indexes indicate that all the cases presenting a low filling degree are largely affected by mechanical weakening, with the exception of AL1 and BL1. Finally, it is worth mentioning that in the val- 

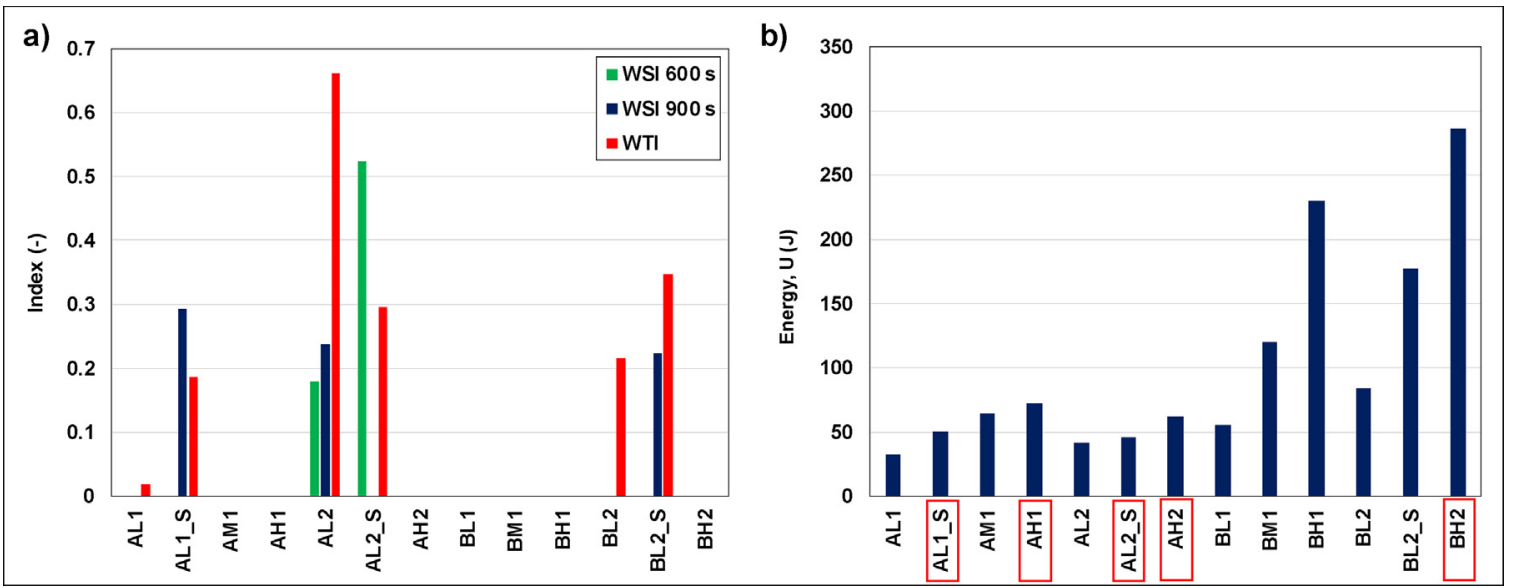

Fig. 11 - a) WSI (at 600 and 900 s simulation time) and WTI values calculated for all the case studies, b) energy U accumulated before the PSV opening (case highlighted with a red rectangle) or the end of the test. (For interpretation of the references to color in this figure legend, the reader is referred to the web version of this article.)

idation case (similar to the AL1 case) the wall temperature never reached the $400^{\circ} \mathrm{C}$. Therefore, WSI and WTI are both null.

Fig. 11b compares the energy accumulated during the fire exposure until the PSV opening (or the end of the simulation, for the cases in which the PSV opening did not occur). As expected, this quantity increases with the increasing of the liquid level (e.g. cases BL1-BM1-BH1) and the volume of the vessel. Comparing Fig. 11a and $\mathrm{b}$ it appears that the critical weakening scenarios, e.g. the cases for which the higher WSI and WTI values are calculated, are associated to a limited energy accumulation in the tank lading, corresponding to lower U values. Consequently, this indicates that a lower severity of the possible consequent scenarios is expected, due to the limited energy available for missile projection (Tugnoli et al., 2014a, 2014b), blast associated to a BLEVE (Abbasi and Abbasi, 2007; Casal and Salla, 2006; Chen et al., 2008; Lautkaski, 2009; Salla et al., 2006; Stawczyk, 2003) and fireball (Maillette and Birk, 1996; Roberts, 1982) hazards following the rupture (Birk and Cunningham, 1996), if weakening leads to vessel failure. It should thus be remarked that the simultaneous modeling of both thermal weakening of the vessel and energy accumulation may support a more detailed consequence analysis of critical accidents induced by forest fires.

\section{Conclusions}

In the present study, an integrated experimental and numerical approach was adopted in order to derive specific information on the resistance of LPG vessels exposed to wildland fires radiation. Large scale experimental tests allowed obtaining pressure and temperature data able to characterize the heat-up of vessels exposed to distant source radiation. A dedicated 2D CFD model was then developed and validated against the available experimental data in order to obtain a prediction tool for the simulation of several case studies. A specific UDF allowed simulating different fire exposure modes and transient heat radiation values. Several case studies were analyzed in order to quantify the effect of tank geometry, filling level, symmetric and asymmetric fire exposure conditions on the vessel response to wildland fires and the consequent pressurization rates. A simplified assessment of vessel weakening due to fire and energy accumulation was carried out through the definition of key performance indicators.
The results showed that high filling level as well as symmetric fire conditions lead to faster pressurization of the tanks, thus with a more limited energy accumulation. Low filling level conditions combined with more severe fires strongly affect the steel weakening. In this case, however, the limited energy accumulation may lead to failure scenarios featuring less severe consequences. Therefore, the outcomes of the present study may contribute to the characterization of critical accidents induced by forest fires in Wildland-Urban Interface, which is of utmost importance to support the safe response of fire-fighters during emergency operations.

\section{Appendix A.}

\section{A.1 Fire scenario scaling}

In the present section, an overview of the scaling procedure applied by Heymes et al. (2013b) is presented. The commonly adopted approach for the analysis of scenarios involving targets exposed a distant fire is to idealize the visible flame as a solid body, having a rather simple geometrical shape and emitting a constant thermal radiation. Following this assumption, the heat flux reaching a remote target can be expressed as follows:

$q=\tau f E$

where $\tau$ is the transmissivity of the air (this was conservatively assumed to be 1$), f$ is the view factor between the fire and the target and $E$ is the surface emissive power of the fire. The view factor is a characteristic of the problem geometry. It depends on the fire and target dimensions and distance between them. A homothetic transformation of the problem geometry (i.e. a transformation in which the linear dimensions of the geometry are multiplied by a given factor, with the angles remaining unchanged) leaves the view factor unchanged.

In their work, Heymes et al. (2013b) studied the response of a LPG tank exposed to a fire front with an average emissive power of $90 \mathrm{~kW} / \mathrm{m}^{2}$ featuring the following dimensions: $\mathrm{L}=100 \mathrm{~m}, \mathrm{H}=40 \mathrm{~m}$ (see Fig. A1 for geometrical parameters definition). They considered two scenarios, in which the tank was located at two different distances from the fire: $d=28$ and $\mathrm{d}=50 \mathrm{~m}$ (see Fig. A1 for geometrical parameters definition). 


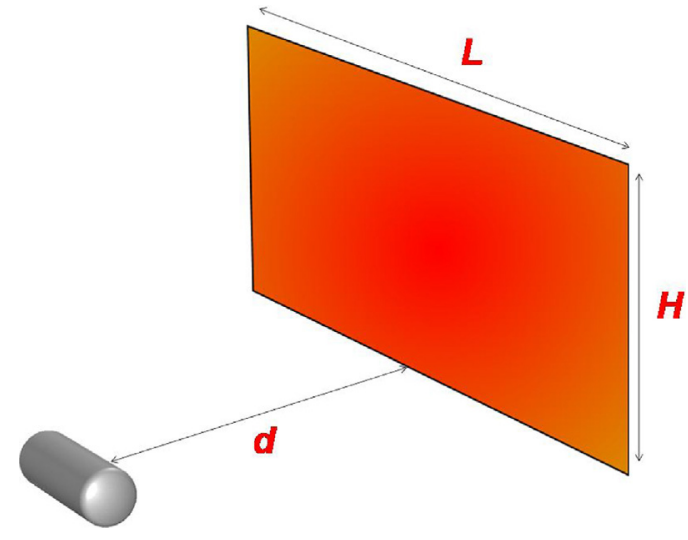

Fig. A1 - Reference geometrical shceme adopted the calculation of the view factor.

In the experimental tests considered in the present work (see Section 2), a real scale tank was considered, while the fire dimensions were reduced due to the fact that, for practical reasons, the fire wall height in the experiments could not exceed $4 \mathrm{~m}$. A simple scale down carried out keeping a constant ratio among the linear dimensions $d, H$ and $L$ (see Fig. A1) would have resulted in wrong representation of the real fire scenario. As showed in (Heymes et al., 2013b), the view fac- tor obtained with such scaling procedure increases when $d$ is reduced, leading to considerable differences between the values of the maximum incident heat flux (MHF) and the total incident thermal power (TTP) reaching the tank with respect to the real scale scenario. MHF (Eq. (A.2)) is the flux registered in the point of the tank surface with the highest values of the local view factor. TTP (Eq. (A.3)) is the integral over the surface of the tank $\left(\mathrm{S}_{\mathrm{t}}\right)$ of the product between the fire emissive power and the local view factor; in particular

$\mathrm{MHF}=f_{\max } \mathrm{E}$

$\mathrm{TTP}=f E$

$S_{t}$

Due to the above-mentioned consideration, a different scaling criterion was needed. The aim was to define a test geometry so that the value of these two parameters were as close as possible to those characteristics of the real case, but, on the same time, keeping the limit of $4 \mathrm{~m}$ for the fire wall height. Heymes et al. (2013b) calculated the view factor for a large set of cases varying $d, L$ and $H$. This was done using a finite element analysis (i.e. discretizing the tank and the fire wall surface with small elements), following an approach similar to the one pre-

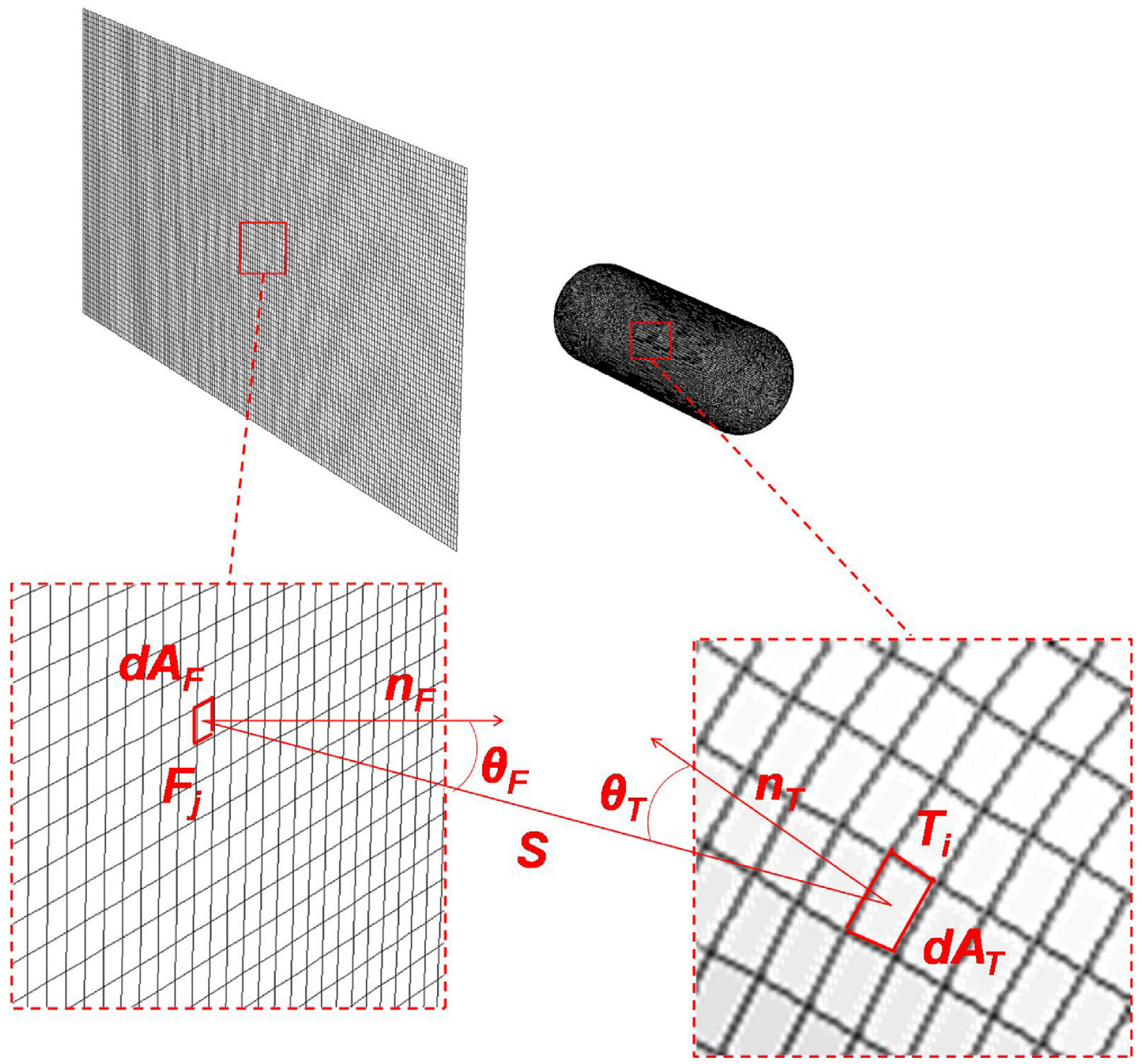

Fig. A2 - 3D mesh and paramters definition for the calculation of the view factors. The description of the parameters represented in the pictures are explained in the text. 
sented in Appendix A.2. The results of this analysis led to the definition of the experimental scale geometry parameters reported in Table 1 and object of the present study. It can be noticed how values of both maximum incident heat flux and total incident thermal power for the real and the experimental scale scenarios are very similar.

\section{A.2 View factors calculation}

The present section illustrates the procedure for the calculation of the view factors implemented in the 2D CFD model.

As explained in Section 3.1, the 3D problem geometry was firstly reproduced. The outer wall surface of the tank was meshed with elements of maximum edge length of $1 \mathrm{~cm}$. Elements of maximum edge length of $4 \mathrm{~cm}$ were instead used to mesh the fire wall, as showed in Fig. A2 (a grid independence study was also carried out by using a maximum edge length of 0.5 and $2 \mathrm{~cm}$ for the tank and the fire wall respectively).

Considering an element $T_{i}$ of area $d A_{T}$ on the surface of the tank and an element $F_{j}$ of area $d A_{F}$ on the surface of the fire wall, the view factor $f_{\text {TF }}$ between them is defined as the fraction of the radiation leaving the surface $F_{j}$ that is intercepted by a surface $T_{i}$. Oriented elementary areas $d A_{F}$ and $d A_{T}$ are connected by a line of length $S$ which defines the polar angles $\theta_{\mathrm{F}}$ and $\theta_{\mathrm{T}}$, respectively, with the surface normal vectors $n_{F}$ and $n_{T}$. The values of $S, \theta_{F}$ and $\theta_{T}$ vary as function of the position of the elemental areas on $F$ and $T$.

Assuming that both surfaces emit and reflect diffusely, and that the radiosity is uniform, the view factor can be analytically defined as:

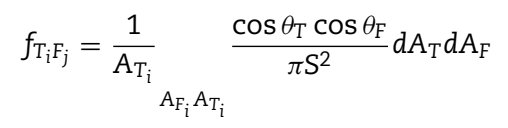

In ANSYS Fluent, the S2S (surface to surface) model discretizes Eq. (A.4) according to the mesh. The view factor between each element on the tank surface and the entire fire wall is then calculated as:

$f_{T_{i} F}=\quad \frac{\cos \theta_{T} \cos \theta_{F}}{\pi S^{2}} d A_{F_{j}}$

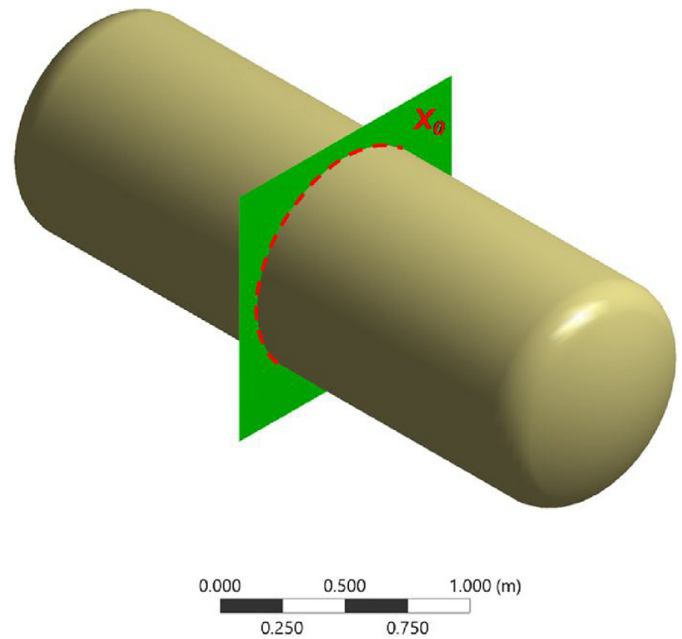

Fig. A3 - Schematic representation of the section in which the view factors are calculated for the 2D CFD simulation.

In this way, the view factor $f_{T_{i} F}$ as been calculated for each element of the tank outer wall. In principle, it is possible to use them for a 3D simulation of the vessel response to fire exposure. However, in the present work, only a 2D simulation of a vertical section in the middle of the tank was carried out as explained is Section 3.1. For the sake of clarity, the section considered for the simulation is highlighted by the vertical plane in Fig. A3. For this reason, only the values of the view factors associated with the elements lying on the dashed line (labelled as $\mathrm{X}_{0}$ in Fig. A3) were considered for the definition of the boundary condition in the $2 \mathrm{D}$ simulation. These view factors are adopted in Eq. (3b) as explained in Section 3.3 and indicated as $f_{P \rightarrow F}$, since $P$ is the generic point on $X_{0}$ and $F$ is the fire.

\section{A.3 UDF for the definition of the boundary condition}

The detailed User Defined Function for the set-up of boundary conditions is reported in detail in Fig. A4. 


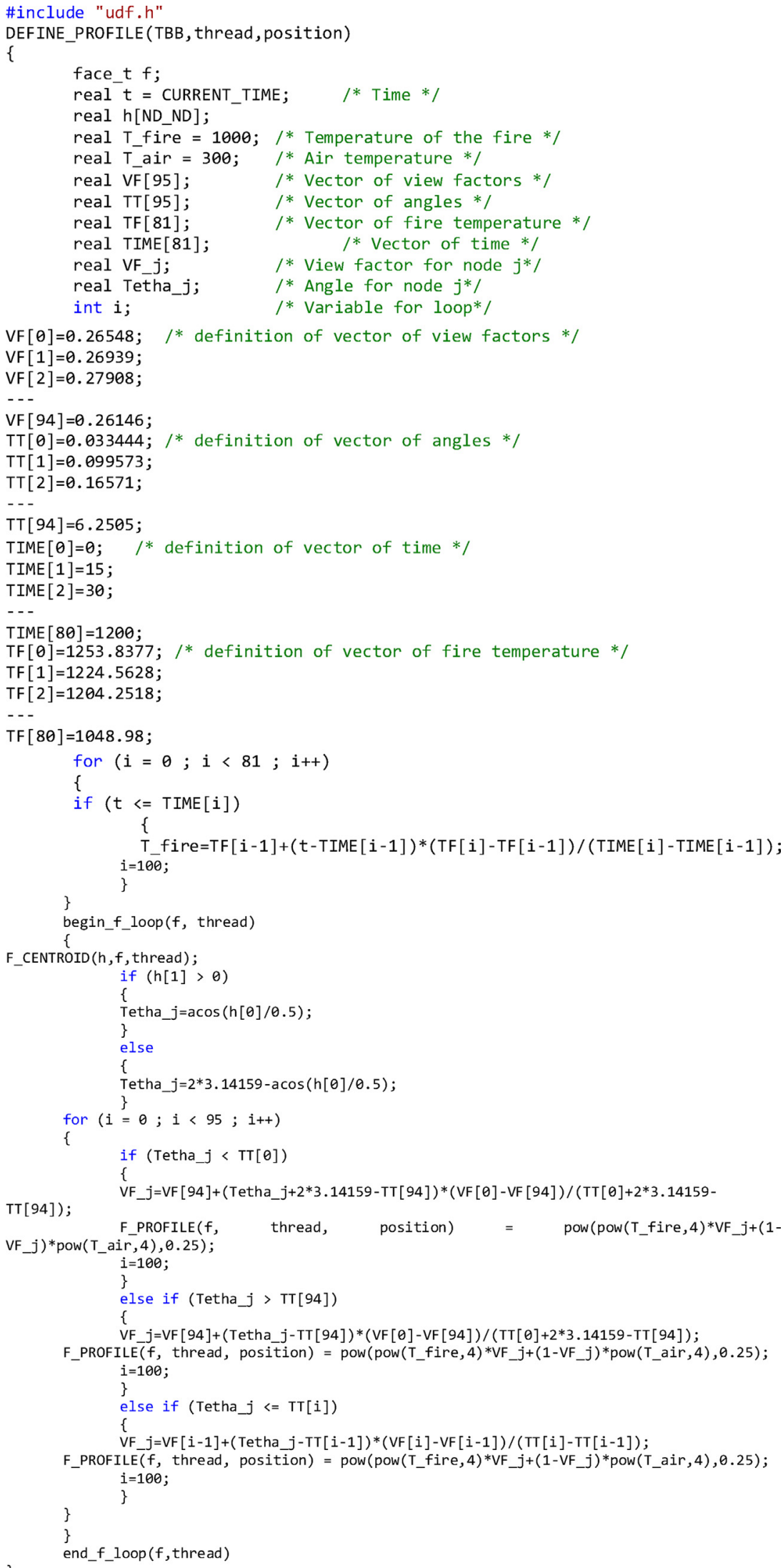

Fig. A4 - User defined funtion adopted to implement heaf flux boundary conditions in the 2D CFD simulations.

\section{References}

Abbasi, T., Abbasi, S.A., 2007. The boiling liquid expanding vapour explosion (BLEVE): mechanism, consequence assessment, management. J. Hazard. Mater. 141, 489-519.
Ager, A.A., Vaillant, N.M., Finney, M.A., 2010. A comparison of landscape fuel treatment strategies to mitigate wildland fire risk in the urban interface and preserve old forest structure. For. Ecol. Manage. 259, 1556-1570.

Alcasena, F.J., Salis, M., Ager, A.A., Arca, B., Molina, D., Spano, D., 2015. Assessing landscape scale wildfire exposure for highly 
valued resources in a Mediterranean area. Environ. Manage. 55, 1200-1216.

ANSYS inc, 2012. ANSYS ${ }^{\oplus}$ FLUENT $^{\oplus} 14.5$ Theory Guide. ANSYS Inc., Cecil Township, PA.

Argañaraz, J.P., Radeloff, V.C., Bar-Massada, A., Gavier-Pizarro, G.I., Scavuzzo, C.M., Bellis, L.M., 2017. Assessing wildfire exposure in the Wildland-Urban Interface area of the mountains of central Argentina. J. Environ. Manage. 196, 499-510.

Aydemir, N.U., Magapu, V., Sousa, A., Venart, J.E.S., 1988. Thermal response analysis of LPG tanks exposed to fire. J. Hazard. Mater. 20, 239-262.

Bi, M.S., Ren, J.J., Zhao, B., Che, W., 2011. Effect of fire engulfment on thermal response of LPG tanks. J. Hazard. Mater. 192, 874-879.

Billaud, Y., Kaiss, A., Consalvi, J.L., Porterie, B., 2011. Monte Carlo estimation of thermal radiation from wildland fires. Int. J. Therm. Sci. 50, 2-11.

Birk, A., 1989. Modelling the effects of a torch-type fire impingement on a rail or highway tanker. Fire Saf. J. 15, 277-296.

Birk, A., 1995. Scale effects with fire exposure of pressure-liquified gas tanks. Loss Prev. Process Ind. 8, 275-290

Birk, A., Cunningham, M.H., 1994. The boiling liquid expanding vapour explosion. J. Loss Prev. Process Ind. 7, 474-480.

Birk, A., Cunningham, M.H., 1996. Liquid temperature stratification and its effect on BLEVEs and their hazards. J. Hazard. Mater. 48, 219-237.

Butler, B., Cohen, J., 1998. Firefighter safety zones: a theoretical model based on radiative heating. Int. J. Wildl. Fire 8, 73-77.

Cardil, A., Molina, D.M., 2015. Factors causing victims of wildland fires in Spain (1980-2010). Hum. Ecol. Risk Assess. Int. J. 21, 67-80.

Casal, J., Salla, J.M., 2006. Using liquid superheating energy for a quick estimation of overpressure in BLEVEs and similar explosions. J. Hazard. Mater. 137, 1321-1327.

CEN - European Committee for Standardization, 1998. EN 10222-1. Steel Forgings for Pressure Purposes. Part 1: General Requirements for Open Die Forgings. European Committee for Standardization, Brussels, Belgium.

Chen, S., Sun, J., Wan, W., 2008. Boiling liquid expanding vapor explosion: experimental research in the evolution of the two-phase flow and over-pressure. J. Hazard. Mater. 156, 530-537.

D’Aulisa, A., Simone, D., Landucci, G., Tugnoli, A., Cozzani, V., Birk, M., 2014a. Numerical simulation of tanks containing pressurized gas exposed to accidental fires: evaluation of the transient heat up. Chem. Eng. Trans. 36, 241-246, http://dx.doi.org/10.3303/CET1436041.

D’Aulisa, A., Tugnoli, A., Cozzani, V., Landucci, G., Birk, A.M., 2014b. CFD modeling of LPG vessels under fire exposure conditions. AIChE J. 60, 4292-4305.

Dancer, D., Sallet, D.W., 1990. Pressure and temperature response of liquefied gases in containers and pressure vessels which are subjected to accidental heat input. J. Hazard. Mater. 25, 3-18.

Dimitrakopoulos, A., Gogi, C., Stamatelos, G., Mitsopoulos, I., 2011. Statistical analysis of the fire environment of large forest fires (>1000 ha) in Greece. Pol. J. Environ. Stud. 20, 327-332.

Droste, B., Schoen, W., 1988. Full scale fire tests with unprotected and thermal insulated LPG storage tanks. J. Hazard. Mater. 20, 41-53.

European Commission, 2005. EN 1993-1-2, Eurocode 1: actions on structures-part 1-2: general actions-actions on structures exposed to fire, Eurocode 1.

Gettle, G., Rice, C.L., 2002. Criteria for Determining the Safe Separation Between Structures and Wildlands. Millpress, Rotterdam (NL).

Gill, A., Trollope, W., McArthur, D., 1978. Role of moisture in the flammability of natural fuels in the laboratory. Aust. For. Res. 8, 199-208.

Gray, C., Jenkins, M.J., 2017. Climate warming alters fuels across elevational gradients in Great Basin bristlecone pine-dominated sky island forests. For. Ecol. Manage. 392, 125-136.

Hadjisophocleous, G.V., Sousa, A.C.M., Venart, J.E.S., 1990. A study of the effect of the tank diameter on the thermal stratification in LPG tanks subjected to fire engulfment. J. Hazard. Mater. 25, 19-31.

Heymes, F., Aprin, L., Birk, A.M., Slangen, P., Jarry, J.B., François, H., Dusserre, G., 2013a. An experimental study of an LPG tank at low filling level heated by a remote wall fire. J. Loss Prev. Process Ind. 26, 1484-1491.

Heymes, F., Aprin, L., Forestier, S., Slangen, P., Baptiste, J., François, H., Dusserre, G., 2013b. Impact of a distant wildland fire on an LPG tank. Fire Saf. J. 61, 100-107.

Heymes, F., Aprin, L., Forestier, S., Dusserre, G., 2014. Safety of a domestic LPG tank submitted to a forest fire. In: Safety, Reliability and Risk Analysis: Beyond the Horizon Proceedings of the European Safety and Reliability Conference 2013, ESREL, 2013, pp. 211-217.

HSE-Health Safety Executive, 2009. Safe Use of Liquefied Petroleum Gas (LPG) at Small Commercial and Industrial Bulk Installations. Health and Safety Executive, London, UK.

Keane, R.E., Burgan, R., Van Wagtendonk, J., 2001. Mapping wildland fuels for fire management across multiple scales: integrating remote sensing, GIS, and biophysical modeling. Int. J. Wildl. Fire 10, 301-319.

Knudsen, M., 1934. The Kinetic Theory of Gases. Some Modern Aspects. Methuen and Co., Ltd., London, UK.

Lampin-Maillet, C., Jappiot, M., Long, M., Bouillon, C., Morge, D., Ferrier, J.P., 2010. Mapping wildland-urban interfaces at large scales integrating housing density and vegetation aggregation for fire prevention in the South of France. J. Environ. Manage. 91, 732-741.

Lampin-Maillet, C., Jappiot, M., Long, M., Morge, D., Ferrier, J.P., 2009. Characterization and mapping of dwelling types for forest fire prevention. Comput. Environ. Urban Syst. 33, 224-232.

Landucci, G., Cozzani, V., Birk, M., 2013. Heat radiation effects. In: Domino Effects in the Process Industries: Modelling, Prevention and Managing. Elsevier, Amsterdam, The Netherlands, pp. 70-115

Landucci, G., D’Aulisa, A., Tugnoli, A., Cozzani, V., Birk, A.M., 2016. Modeling heat transfer and pressure build-up in LPG vessels exposed to fires. Int. J. Therm. Sci. 104, 228-244.

Landucci, G., Gubinelli, G., Antonioni, G., Cozzani, V., 2009. The assessment of the damage probability of storage tanks in domino events triggered by fire. Accid. Anal. Prev. 41, 1206-1215.

Launder, B.E., Spalding, D.B., 1972. Lectures in Mathematical Models of Turbulence. Academic Press, London, UK.

Lautenberger, C., 2013. Wildland fire modeling with an Eulerian level set method and automated calibration. Fire Saf. J. 62, 289-298.

Lautkaski, R., 2009. Evaluation of BLEVE risks of tank wagons carrying flammable liquids. J. Loss Prev. Process Ind. 22, 117-123.

Lees, F.P., 1996. Loss Prevention in the Process Industries, 2nd ed. Butterworth - Heinemann, Oxford.

Leuven, K.U., 2006. CFD Calculation of Convective Heat Transfer Coefficients and Validation - Part 2: Turbulent Flow Annex 41-Kyoto, April 3, pp. 1-20.

Liley, P.E., Thomson, G.H., Friend, D.G., Daubert, T.E., Buck, E., 1999. Physical and chemical data, Section 2. In: Perry's Chemical Engineers' Handbook. McGraw Hill, New York, NY.

Lin, W., Gong, Y., Gao, T., Gu, A., Lu, X., 2010. Experimental studies on the thermal stratification and its influence on BLEVEs. Exp. Therm. Fluid Sci. 34, 972-978.

Maillette, J., Birk, A.M., 1996. Influence of Release Conditions on Bleve Fireballs. American Society of Mechanical Engineers, Pressure Vessels and Piping Division (Publication) PVP, pp. 147-152.

Manu, C.C., Birk, A.M., Kim, I.Y., 2009. Stress rupture predictions of pressure vessels exposed to fully engulfing and local 
impingement accidental fire heat loads. Eng. Fail. Anal. 16, 1141-1152.

Martynenko, O.G., Khramtsov, P.P., 2005. Free-convective Heat Transfer. Springer-Verlag, Berlin Heidelberg, Germany.

Monedero, S., Ramirez, J., Molina-Terrén, D., Cardil, A., 2017. Simulating wildfires backwards in time from the final fire perimeter in point-functional fire models. Environ. Model. Softw. 92, 163-168.

Moodie, K., 1988. Experiments and modelling—an overview with particular reference to fire engulfment. J. Hazard. Mater. 20, 149-175.

Pierce Jr., K.B., Ohmann, J.L., Wimberly, M.C., Gregory, M.J., Fried, J.S., 2009. Mapping wildland fuels and forest structure for land management: a comparison of nearest neighbor imputation and other methods. Can. J. For. Res. 39, 1901-1916, http://dx.doi.org/10.1139/X09-102.

Rebec, A., Kolšek, J., Plešec, P., 2016. Fires in storages of LFO: analysis of hazard of structural collapse of steel-aluminium containers. J. Hazard. Mater. 306, 367-375.

Reid, R.C., 1979. Possible mechanism for pressurized-liquid tank explosions or BLEVE's. Science 203 (March (4386)), 1263-1265.

Roberts, A.F., 1982. The effect of conditions prior to loss of containment on fireball behavior. In: The Assessment of Major Hazards. Institution of Chemical Engineers, Rugby (UK)

Rossi, J.L., Simeoni, A., Moretti, B., Leroy-Cancellieri, V., 2011. An analytical model based on radiative heating for the determination of safety distances for wildland fires. Fire Saf. J. $46,520-527$.

Salla, J.M., Demichela, M., Casal, J., 2006. BLEVE: a new approach to the superheat limit temperature. J. Loss Prev. Process Ind. 19, 690-700.

Salzano, E., Picozzi, B., Vaccaro, S., Ciambelli, P., 2003. Hazard of pressurized tanks involved in fires. Ind. Eng. Chem. Res., 1804-1812.

Scarponi, G.E., Landucci, G., Tugnoli, A., Cozzani, V., Michael, A., 2016. Performance assessment of thermal protection coatings of hazardous material tankers in the presence of defects. Process Saf. Environ. Prot. 105, 393-409.

SCI-Steel Construction Institute, 1992. Passive Fire Protection: Performance Requirements and Test Methods, OTI92606. Health and Safety Executive, HM Stationery Office, London, UK.

Shebeko, Y.N., Smolin, I.M., Korolchenko, A.Y., Shevchuk, A.P., Borodkin, A.N., Malkin, V.L., Simonov, A., Gurinovich, L.V., Popov, S.A., Kolosov, V.A., Smirnov V, E., 1995. Some aspects of fire and explosion hazards of large LPG storage vessels. J. Loss Prev. Process Ind. 8, 163-168.
Shi, J., Bi, M., Yang, X., 2012. Experimental research on thermal stratification of liquefied gas in tanks under external thermal attack. Exp. Therm. Fluid Sci. 41, 77-83.

Stawczyk, J., 2003. Experimental evaluation of LPG tank explosion hazards. J. Hazard. Mater. 96, 189-200.

Sullivan, A.L., Ellis, P.F., Knight, I.K., 2003. A review of radiative heat flux models used in bushfire applications. Int. J. Wildl. Fire 12, 101-110.

Townsend, W., Anderson, C., Zook, J., Cowgill, G., 1974. Comparison of Thermally Coated and Uninsulated Rail Tank-cars Filled With LPG Subjected to a Fire Environment. US Department of Transportation, Washington DC.

Tran, H.C., Cohen, J.D., Chase, R.A., 1992. Modeling ignition of structures in wildland-urban interface fires. In: Proceedings of the 1st International Fire and Materials Conference, Arlington, VA, pp. 253-262.

Tu, J., Yeoh, G., Liu, C., 2013. Computational Fluid Dynamics. A Practical Approach, 2nd ed. Butterworth-Heinemann, Waltham, MA (US).

Tugnoli, A., Gubinelli, G., Landucci, G., Cozzani, V., 2014a. Assessment of fragment projection hazard: probability distributions for the initial direction of fragments. J. Hazard. Mater. 279C, 418-427.

Tugnoli, A., Milazzo, M.F., Landucci, G., Cozzani, V., Maschio, G., 2014b. Assessment of the hazard due to fragment projection: a case study. J. Loss Prev. Process Ind. 28, 36-46.

Van Den Bosh, C.J.H., Weterings, R.A.P.M., 2005. Methods for the calculation of physical effects (Yellow Book). In: Committee for the Prevention of Disasters, third ed. the Hague (NL).

Yu, C.M., Aydemir, N.U., Venart, J.E.S., 1992. Transient free convection and thermal stratification in uniformly-heated partially-filled horizontal cylindrical and spherical vessels. J. Therm. Sci. 1, 114-122.

Wu, H.L., Peng, X.F., Ye, P., Eric Gong, Y., 2007. Simulation of refrigerant flow boiling in serpentine tubes. Int. J. Heat Mass Transfer 50 (5-6), 1186-1195.

Zárate, L., Arnaldos, J., Casal, J., 2008. Establishing safety distances for wildland fires. Fire Saf. J. 43, 565-575.

Zheng, J., Ou, K., Bie, H., Xu, P., Zhao, Y., Liu, X., He, Y., 2012. Heat transfer analysis of high-pressure hydrogen storage tanks subjected to localized fire. Int. J. Hydrogen Energy 37, 13125-13131.

Zheng, J., Ou, K., Hua, Z., Zhao, Y., Xu, P., Hu, J., Han, B., 2013. Experimental and numerical investigation of localized fire test for high-pressure hydrogen storage tanks. Int. J. Hydrogen Energy 38, 10963-10970. 